Document downloaded from:

http://hdl.handle.net/10251/161379

This paper must be cited as:

Serrano, J.; Olmeda, P.; Arnau Martínez, FJ.; Samala, V. (2020). A holistic methodology to correct heat transfer and bearing friction losses from hot turbocharger maps in order to obtain adiabatic efficiency of the turbomachinery. International Journal of Engine Research. 21(8):1314-1335. https://doi.org/10.1177/1468087419834194

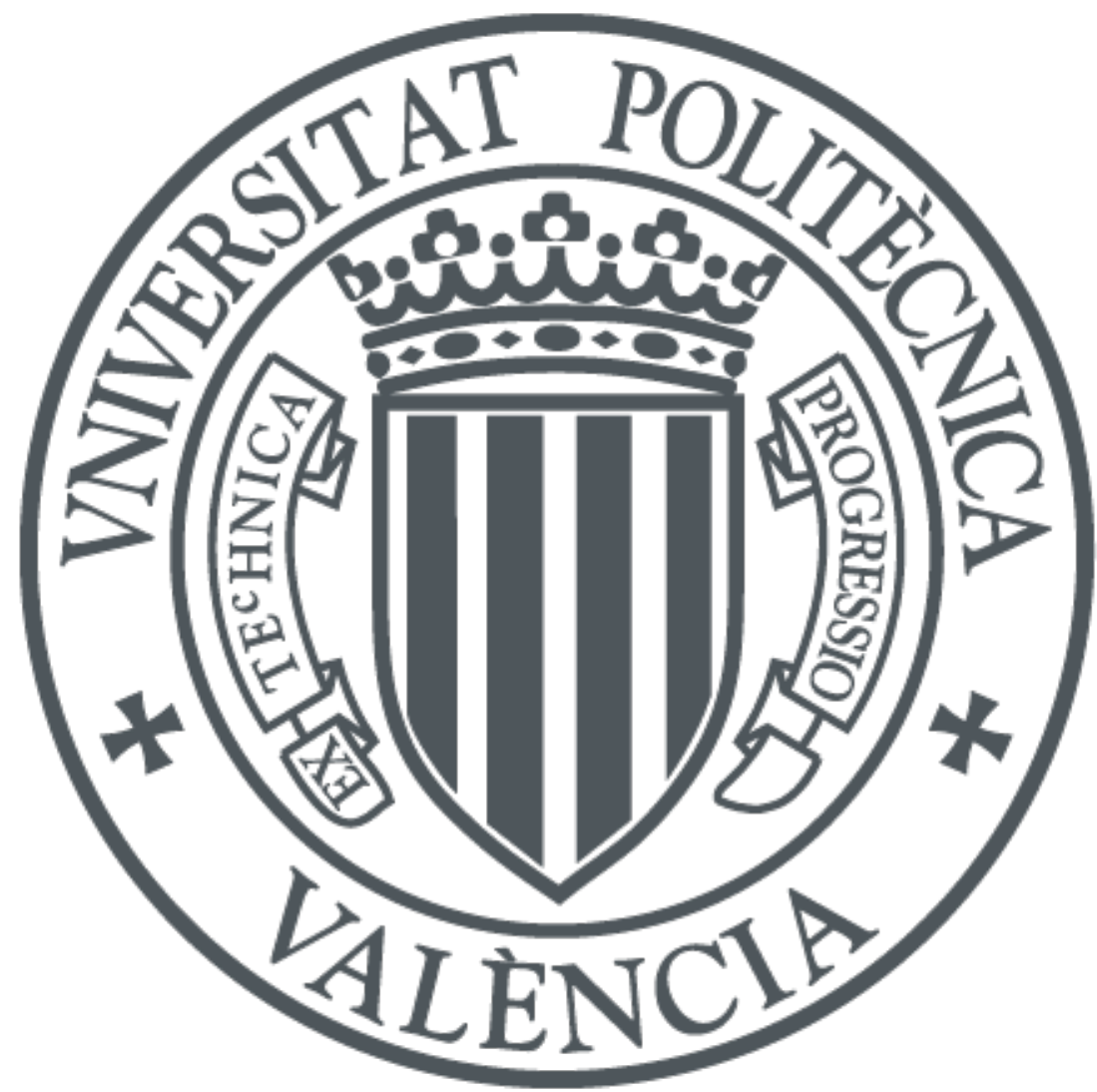

The final publication is available at

https://doi.org/10.1177/1468087419834194

Copyright SAGE Publications

Additional Information

This is the author is version of a work that was accepted for publication in International Journal of Engine Research. Changes resulting from the publishing process, such as peer review, editing, corrections, structural formatting, and other quality control mechanisms may not be reflected in this document. Changes may have been made to this work since it was submitted for publication. A definitive version was subsequently published as https://doi.org/10.1177/1468087419834194 


\section{A holistic methodology to correct heat transfer and bearing friction losses from hot \\ turbocharger maps in \\ order to obtain \\ adiabatic efficiency of the turbo-machinery}

José R. Serrano", Pablo Olmeda*, Francisco J. Arnau ${ }^{\star \star}$ and Vishnu Samala* 


\begin{abstract}
Turbocharger performance maps provided by manufacturers are usually far from the assumption of reproducing the isentropic performance. The reason being, those maps are usually measured using a hot gas stand. The definition of the effective turbocharger efficiency maps include the mechanical losses and heat transfer that has occurred during the gas stand test for the turbine maps and only the heat transfer for the compressor maps. Thus, a turbocharger engine model that uses these maps provides accurate results only when simulating turbocharger operative conditions similar to those at which the maps are recorded. However, for some critical situations such as WLTC driving cycle or off-design conditions, it is difficult to ensure this assumption. In the present paper, an internal and external heat transfer model joint with a mechanical losses model, both previously developed and calibrated has been used as an original tool to ascertain a calculation procedure to obtain adiabatic maps from diabatic standard turbocharger maps. The turbocharger working operative conditions at the time of map measurements and geometrical information of the turbocharger are necessary to discount both effects precisely. However, the maps from turbocharger manufacturers do not include all required information. These create additional challenges to develop the procedure to obtain approximated adiabatic maps making some assumptions based on SAE standards for non-available data. A sensitivity study has been included in this paper to check the validity of the hypothesis proposed by changing the values of parameters which are not included in the map data. The proposed procedure becomes a valuable tool either for OEMs to parameterize turbocharger performance accurately for benchmarking and turbocharged engine design or to turbocharger manufacturers to provide muchappreciated information of there performance maps.
\end{abstract}

\title{
Keywords
}

Turbocharging, Waste-gate, Discharge Coefficient, Experimental, Modeling

\section{Nomenclature}

\section{Corresponding author:}

Francisco J. Arnau, CMT-Motores Térmicos, Universitat Politècnica de València, Camino de Vera s/n. 46022 València, Spain, www.cmt.upv.es, Tel: +34963877650, fax: +34963877659

Email: farnau@mot.upv.es 


$\begin{array}{lll}A_{e f f} & \text { Effective Area } & \mathrm{m}^{2} \\ C_{T} & \text { Thermal Capacitance of the Turbine node } & \mathrm{J} \cdot \mathrm{K}^{-1} \\ C_{H 1} & \text { Thermal Capacitance of the Housing node close to the turbine } & \mathrm{J} \cdot \mathrm{K}^{-1} \\ C_{H 2} & \text { Thermal Capacitance of the Central housing node } & \mathrm{J} \cdot \mathrm{K}^{-1} \\ C_{H 3} & \text { Thermal Capacitance of the Housing node close to the compressor } & \mathrm{J} \cdot \mathrm{K}^{-1} \\ C_{c} & \text { Thermal Capacitance of the Compressor node } & \mathrm{J} \cdot \mathrm{K}^{-1} \\ c & \text { Specific heat capacity } & \mathrm{J} \cdot \mathrm{kg}^{-1} \cdot \mathrm{K}^{-1} \\ C & \text { Compressor node } & - \\ C_{s} & \text { Contact surface average diameter } & \mathrm{m} \\ D & \text { Diameter } & \mathrm{m} \\ D_{e f f} & \text { Effective Diameter } & \mathrm{m} \\ D_{m} & \text { Mean Diameter } & \mathrm{m} \\ \text { RMSE } & \text { Root Mean Square Error } & - \\ H & \text { Refers to turbocharger housing } & - \\ H 1 & \text { Housing node close to the turbine } & - \\ H 2 & \text { Central housing node } & - \\ H 3 & \text { Housing node close to the compressor } & - \\ i, j & \text { Generic codes } & - \\ K & \text { Conductance } & \mathrm{W} \cdot \mathrm{K}^{-1} \\ k & \text { Conductivity } & W \cdot \mathrm{m}^{-1} \cdot K^{-1} \\ L & \text { Length } & \mathrm{m}\end{array}$

$\begin{array}{lll}m & \text { Mass } & \mathrm{kg} \\ \dot{m} & \text { Mass flow } & \mathrm{kg} / \mathrm{s} \\ N & \text { Turbocharger Speed } & \mathrm{rpm} \\ p_{T I T} & \text { Total pressure at the turbine inlet } & \mathrm{Pa} \\ p_{T I C} & \text { Total pressure at the compressor inlet } & \mathrm{Pa} \\ \dot{Q} & \text { Heat flow } & \mathrm{W} \\ T & \text { Turbine node } & - \\ T_{T G a s} & \text { Total temperature at the turbine inlet } & \mathrm{K} \\ T_{T G \text { Gas }}^{a d} & \text { Total adiabatic temperature at the turbine inlet } & \mathrm{K} \\ T_{O T}^{a d} & \text { Adiabatic isentropic temperature at the turbine outlet } & K \\ T_{O T}^{a d} & \text { Adiabatic temperature at the turbine outlet } & K \\ T_{T O T} & \text { Total temperature at the turbine outlet } & K \\ T_{T O T}^{a d} & \text { Total adiabatic temperature at the turbine outlet } & K \\ T_{O T, s} & \text { Isentropic temperature at the turbine outlet } & K \\ T_{O T} & \text { Static temperature at the turbine outlet } & K \\ T_{T I C} & \text { Total temperature at the compressor inlet } & K \\ T_{T O C} & \text { Total temperature at the compressor outlet } & K \\ T_{T \text { Tir }}^{a d} & \text { Total adiabatic temperature at the compressor outlet } & K\end{array}$


$T_{O I} \quad$ Oil inlet temperature $\quad K$

$T_{O O} \quad$ Oil outlet temperature $K$

$T_{W I} \quad$ Water Inlet temperature $K$

$\dot{W}_{m} \quad$ Mechanical power $\quad W$

$\dot{W}_{T} \quad$ Turbine power $\quad W$

$\dot{W}_{T, s} \quad$ Isentropic turbine power $\quad W$

$\dot{W}_{T}^{a d}$ Adiabatic turbine power $W$

$\dot{W}_{T, s}^{a d} \quad$ Isentropic adiabatic turbine power $\quad W$

$\dot{W}_{C} \quad$ Compressor power $W$

$\dot{W}_{C}^{a d}$ Adiabatic compressor power $W$

$\dot{W}_{C, s} \quad$ Isentropic compressor power $W$

$\alpha \quad$ Turbine capacitance fitting constant -

$\beta \quad$ Housing capacitance fitting constant -

$\gamma \quad$ Housing capacitance fitting constant -

$\rho$ Density $\mathrm{kg} / \mathrm{m}^{3}$

$\epsilon \quad$ Compressor capacitance fitting constant -

$\theta \quad$ Geometry fitting constant -

$\eta_{c} \quad$ Compressor Efficiency -

$\eta_{T} \quad$ Turbine Efficiency - 


\section{Introduction}

The Internal Combustion Engines (ICE) efficiency and power output are improved steadily by the use of turbochargers. The importance of turbocharger has been given mainly by the emphasis on reducing the exhaust emissions and improving the fuel economy which results in downsizing the engines.

The turbochargers are optimized at medium to high loads on an engine. At low engine load, their behavior is not optimized. The flow is usually non-adiabatic (diathermal or diabatic) in the turbo compressors. However, both heat transfer and work input are included in the compression process definition ${ }^{1}$. The process of turbo compressors is highly dependent on both operating points and inlet conditions ${ }^{2}$. Therefore, a procedure for calculation of mechanical losses and heat transfer is essential so that its behavior can be predicted accurately. Thus, the adiabatic maps would be obtained for both compressor and turbine due to this separation of effects. The adiabatic maps are the maps which consider only the aerodynamic effects and therefore they can be extrapolated with physical models of losses or empirical models ${ }^{3}$. Further on, other losses such as mechanical friction and heat can be added to them.

The procedure to obtain the adiabatic maps are shown in a variety of works by doing some experiments and modeling which are already published by different authors. However, there is no clear information for obtaining the adiabatic maps from turbocharger manufacturer maps.In a study published by Nakhjiri et al. ${ }^{4}$, compressor maps were shown at different heat flow levels. The authors observed no deterioration in the pressure ratio of the compressor. Hence, they concluded that the temperature of air flowing through compressor increases with the transfer of heat mainly after the compression process. Thus, the aerodynamic efficiency of the compressor will be the same if both pressure ratio and mass flow are the same.

Chesse et al. ${ }^{5}$ concluded that the automotive turbocharger compressors are not adiabatic and they depend on turbine inlet temperatures. Experimentally they attested that the influence of internal heat transfer is not important if compared to turbocharger mechanical power at high engine loads. The experimental activity was developed in adiabatic conditions by altering the average turbine temperature to average compressor temperature. The turbocharger was thermally insulated to minimize the external heat transfer.

Sidorow et al. ${ }^{6}$ presented two different turbocharger modeling approaches one based on thermodynamics and other fluid dynamic, considering both heat inflow into the compressor and outflow from the turbine. Both approaches were validated against measurements performed on a dynamic engine test bench. Both models proposed by them seem to suitable for onboard fault diagnosis.

Zimmermann et al. $^{7}$ showed a procedure to evaluate the quality of the adiabatic measurements and compare them with the standard measurements. The approach is to identify a relatively constant heat transfer rate with the turbocharger speed; for this, a total turbine enthalpy drop is represented against the isentropic compressor power. Considering the points of a maximum isentropic compressor power for each speedline; its presentation leads to the assumption of linearity. They assumed that all the turbine 
power is used to be converted into compressor power. When the required compressor power reaches zero (i.e., at zero speed), the turbine power has to be down to zero as well. These indicate almost adiabatic measurements. Every deviation from zero at the axis ordinates are influenced by heat flows. However, the method did not show how the manufacturer maps can be used to obtain adiabatic maps. The methodology does not discount mechanical (friction) losses in bearings and shaft, which are usually included in maps definition. They assume that heat flux is independent of turbocharger speed, which is generally incorrect. Even at high speeds (high power) errors in heat flux calculation have minor impact on the turbocharger.

Serrano et $\mathrm{al}^{8}$ presented a methodology to extend the performance of turbocharger turbine at very low expansion ratios and to characterize the adiabatic efficiency in a wide operating range. By using an Inlet Guide Vanes (IGV) at upstream of the compressor, they were able to measure the turbine power from very low up to negative power output. The tests were carried out under quasi-adiabatic conditions with different levels of lubricating oil inlet temperatures to show the impact of internal heat transfer even at quasi-adiabatic measurements. Later they estimated the adiabatic efficiency with the heat transfer model proposed in ${ }^{9}$ then correlated a novel and straight forward method for heat transfer estimation at quasi-adiabatic turbine measurements. The advantages of this procedure are that with few number of measurements, heat transfer can characterize and the quality of the adiabatic measurements can be estimated at the beginning testing stages. Nevertheless, no correction for friction losses had been taken into account.

Marelli et al. ${ }^{10}$ presented a study which only focused on internal heat transfer effects on compressor efficiency with the different values of inlet pressure, mass flow rate, and compressor rotational speed. They tested the turbocharger in hot and adiabatic conditions by using infrared thermography to evaluate the heat transfer rate from the turbine to the compressor. An empirical correlation is proposed based on the experiments to estimate the internal heat transfer rate from bearing housing to the compressor as a function of oil mean temperature and air mean temperature in the compressor with a conductance parameter. However, the information required for this empirical model is not provided by the turbocharger manufacturers on the map to the customer. Consequently, it is not feasible to implement this methodology to get the adiabatic efficiency of the turbine and compressor from turbocharger manufacturer maps.

A simplified one-dimensional(1D) model was proposed by Romagnoli ${ }^{11}$ to obtain the non-adiabatic efficiency of the turbo compressor using multiple regression procedures. In this procedure, there are three parameters with which the efficiency can be correlated; a temperature parameter, pressure ratio, and a Mach number. Though, the procedure did not show how the adiabatic efficiency of the turbine can be obtained. They also did not confirm whether the obtained correlation can be applied to other turbo compressors.

As mentioned by Sirakov et al. ${ }^{2}$, test data are obtained on different small turbochargers with different levels of heat transfer from the turbine to the compressor. The used turbochargers are internal housing cooling, and they tested it in cold and hot gas stands. From the test data, they identified the substantial effects of the heat transfer on the turbine and compressors apparent efficiency, particularly at low mass flows and low speeds. A simplified theory explains the apparent effect of the heat transfer on the efficiency and 
work input. It has been proved by the results that the conventional performance maps underestimate the efficiency of the compressor stage. On the other hand, the efficiency of the turbine is overestimated by around $20 \%$ points when speed is low. For compensating these effects, a correction procedure has been described by assuming a non-dimensional heat transfer coefficient which is constant across the whole performance map. However, this is true if the aerodynamic and thermodynamic effects are small. They concluded that the heat transfer to the compressor is predominately affected by the oil temperature in the bearing housing, but not directly by the turbine inlet temperature itself. However, in turbochargers, the heat transfer to the ambient is not negligible, especially at high compressor ratios in hot exposed conditions. Indeed, the most significant external heat transfer is from the turbine side, due to the big area and high inlet temperature. In comparison the external heat transfer in the central housing is insignificant. On the compressor side, the heat can be lost or gained based on its running conditions. Therefore, the approach might be less effective when the turbocharger is working at high speeds or in transient conditions and the assumption of constant heat transfer coefficient is no longer valid. Moreover, the turbine efficiency overestimation described by Sirakov et al. ${ }^{2}$ has not been confirmed by the experimental and theoretical results further described in this paper. Since the present work proves that the effective turbine efficiency can be either underestimated or overestimated concerning isentropic efficiency and depending on the turbocharger operative conditions. This will be detailed in the results and discussion section of this paper.

\section{Heat transfer and mechanical losses model Description}

The turbocharger thermal model used in this work is based on the electrical analogy. The hypothesis of one-dimensional temperature distribution and one-dimensional heat transfer allow considering the turbocharger as a thermal network consists of a finite number of nodes linked to each other by thermal conductances. To keep in consideration thermal inertia during transient behavior of the turbocharger a thermal capacitance is associated with each node. Figure 1 shows the network of the lumped model. This geometry simplification of the turbocharger in discrete nodes implies the assumption that radial and circumferential temperature distribution in a cross-sectional area is negligible compared to the axial temperature one. It includes the five metal nodes and as many fluid nodes as the fluids in contact with the turbocharger are:

- Node Gas = Exhaust gases moving the turbine

- Node $\mathrm{T}=$ Turbine case node

- Node $\mathrm{H} 1=$ Part of the housing placed near turbine case (turbine housing plate)

- Node H2 = Central part of the housing

- Node H3 = Part of the housing placed near compressor case (compressor backplate)

- Node $\mathrm{C}=$ Compressor case node 
- Node Air = Air passing through the compressor

- Node Oil = Lubricating oil node

- Node $\mathrm{W}=$ Cooling liquid node (only for cooled turbochargers)

- Node Ambient $=$ Ambient node for convective and radiative heat transfer

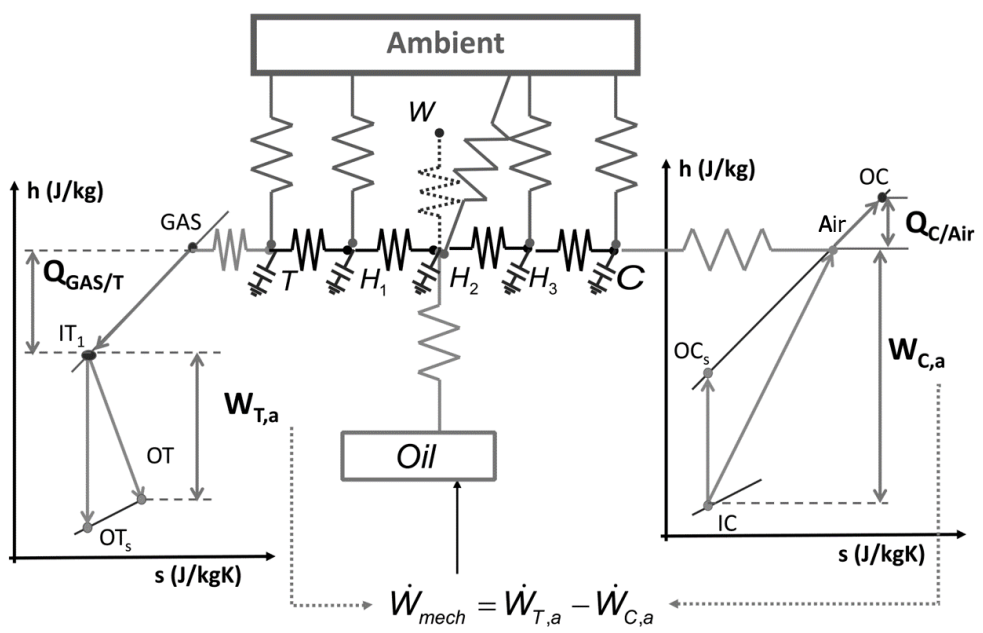

Figure 1. Lumped heat transfer model for turbochargers ${ }^{12}$

It is possible to subdivide all turbocharger heat fluxes in two main groups:

- External heat transfer: It includes heat transfer between metal nodes by radiation and both radiative and convective heat transfer (natural or forced) to the ambient.

- Internal heat transfer: It includes heat transfer by conduction and heat transfer by convection between the metal nodes and the fluids circulating inside the turbocharger.

It is worth highlighting that thermal conductances and capacitances parameters are necessary to perform the calculations of the heat transfer model. In a previous work ${ }^{13}$, these parameters were measured for a given turbocharger unit in a particular gas stand (called as thermohydraulic test bench) using the incompressible flow. In these tests, the temperature of the nodes was measured through thermocouples welded to the metal casings. During the tests, the turbocharger is entirely thermal insulated, to avoid the heat transfer towards the environment, and the shaft is blocked to prevent mechanical power transfer between the turbine and compressor. No oil or water coolant was supplied to the corresponding lube ports. Finally, the thermal oil was passed through the volume of the turbine and compressor casings with a given temperature difference. This whole 
procedure will assure transparent conductive heat transfer problem and separate the turbocharger mechanical power transfer and convective heat transfer problems. With a proper combination of steady state and transient tests and using temperature at the nodes, the conductive conductances and capacitances were obtained. In order to save these experimental costs, a general methodology is proposed in the following section for a variety of turbochargers. The method is based on the previous experience but refining the definition for calculating the area in convective conductances with a physical meaning for different turbochargers. Once the conductances have been determined, the heat transferred between two adjacent nodes is calculated using Fourier's Law (Equation 1) and Newton's Law (Equation 2) respectively when heat transfer is conductive or convective.

$$
\begin{gathered}
\dot{Q}_{i, j}^{c o n d}=K_{i, j} \cdot\left(T_{i}-T_{j}\right) \\
\dot{Q}_{i, j}^{c o n v}=h_{l, i} \cdot A_{l, i} \cdot\left(T_{l}-T_{i}\right)
\end{gathered}
$$

In previous works, the internal convections correlations are already developed by using the experimental data from a gas stand. In those tests, the turbocharger was thermally insulated from outside to avoid heat losses to the ambient ${ }^{9}$. The procedure is based on knowing the conductive conductances of the turbocharger from the specific tests as explained in the above paragraph. The internal convective conductances depend on turbocharger geometry and operative conditions. They are usually calculated through Nusselt number, defined in Equation 3 (where $h$ represents a convective heat transfer coefficient, $D_{h}$ the hydraulic diameter and $k_{f}$ the thermal conductivity of the fluid). It physically represents the ratio between heat transfer by convection and the heat which would be transferred if the fluids were not in motion (i.e., only due fluid conductivity).

$$
\begin{gathered}
N u_{D}=\frac{h \cdot D_{h}}{k_{f}} \\
N u_{D}=0.023 \cdot \operatorname{Re}_{D}^{4 / 5} \cdot \operatorname{Pr}^{c} \\
N u_{D}=0.027 \cdot \operatorname{Re}_{D}^{4 / 5} \cdot \operatorname{Pr}^{1 / 3} \cdot\left(\frac{\mu}{\mu_{w}}\right)
\end{gathered}
$$

In smooth and long pipes Nusselt number is usually determined by Dittus-Boelter or Sieder-Tate correlations (Equations 4 and 5; where the subscript $w$ indicates that the property must be calculated at wall temperature). Turbocharger components geometry is more complicated than the one of a pipe, but experimental research campaigns have demonstrated that ${ }^{9}$, introducing new extra dimensionless number and changing constants coefficients and exponents, the correlations mentioned above give a good prediction for convective heat transfer coefficient calculation in turbochargers too. The diameter of Nusselt number definition for turbocharger components is not the hydraulic diameter, as Equation 3 suggests, but an effective diameter $D_{\text {eff }}$ which changes for 
each studied element. Newton's law and Nusselt number definition lead to Equation 6, which allows calculating heat transfer between generic metal node $i$ and a generic fluid node $f$. As effective diameter, even effective length $L_{e f f}$ is a parameter which describes the geometry of considered element and changes for each one of them. Besides, the temperature difference dt mutates its expression for each component. In previous work ${ }^{9}$, these correlations were developed, and their constants were calibrated with different turbochargers. By these, the model can determine the proper convective heat fluxes for any operative conditions of the turbocharger.

$$
\dot{Q}_{f, i}=N u \cdot k_{f} \cdot \pi \cdot L_{e f f} \cdot \Delta_{T}
$$

In normal working operating conditions, turbine, compressor and housing temperatures are different between each other, then a heat transfer by radiation between them may occur. Furthermore, turbocharger temperature is usually higher than the environment temperature, then a heat transfer from a turbocharger surface to the ambient takes place. The ambient heat transfer includes both convective (forced and natural convection) and radiative heat transfer mechanisms. To determine the external convection and radiation the turbocharger was tested in hot conditions without any thermal insulation to it in a gas stand ${ }^{14}$. For both radiative and convective heat transfer problems, the geometry of the turbocharger is schematized through three cylinders of different diameters ${ }^{14}$. Turbine and compressor thermal surfaces are constituted by three geometrical surfaces: external, cylindrical and internal one. The central housing is divided into three equal surfaces according to the lumped model network. In this way, the calculation of each required view factor is possible and performed by view factor algebra (i.e., reciprocity, closeness, and distribution). Once all the view factors have been characterized, all the heat transfers via radiations are calculated doing the hypothesis of grey surface and uniform temperature for each component. By considering two generic surfaces (1 and 2), the corresponding radiative heat transfer is determined by the Equation 7. Where $\sigma$ is the Stefan Boltzmann constant, $T_{1}$ and $T_{2}$ are the absolute temperatures, $\varepsilon_{1}$ and $\varepsilon_{2}$ are the total emissivities and $F_{1 \rightarrow 2}$ is the view factor of the considered surfaces.

$$
\dot{Q}_{r}=\frac{\sigma \cdot\left(T_{1}^{4}-T_{2}^{4}\right)}{\frac{1-\varepsilon_{1}}{A_{1} \cdot \varepsilon_{1}}+\frac{1}{A_{1} \cdot F_{1 \rightarrow 2}}+\frac{1-\varepsilon_{2}}{A_{2} \cdot \varepsilon_{2}}}
$$

As regard the heat transfer to the ambient by convection, the geometric simplification is the same that radiative heat transfer issue, but only the cylindrical surfaces are taken into account. Three possible situations are considered: natural, forced and mixed convection and there heat transfer convection coefficients were calculated by Nusselt number correlation of Churchill and Chu as explained in ${ }^{14}$. Both radiative and convective heat transfer models have been validated through a large number of experimental analysis and measurements before ${ }^{14}$.

Mechanical losses models developed by Serrano et al ${ }^{15}$ being studied into two different parts $\left(\dot{W}_{m}=\dot{W}_{j b}+\dot{W}_{t b}\right)$ in accordance with turbocharger geometrical characteristics. The bearings are studied with the simplified geometry and their behavior is analyzed 
solving the Navier Stokes equations by some simplifying assumptions. Oil behavior is considered incompressible, and its flow through the bearing is deemed to be steady, constant on each section and circumferentially symmetric. Furthermore, the body forces are neglected, the film thickness is considered smaller than any other bearing part, and viscous stresses are considered comparable to the inertial forces of the fluid (small Reynolds number: $R e=\rho u_{c} / \mu$ ).

Solving Navier-Stokes equations in the journal bearing with those simplifying assumption, the corresponding friction losses are expressed by the Equation 8. As it is observed, those losses depend on shaft rotational speed $(N)$, oil viscosity $(\mu)$ at the average oil temperature $\left(\bar{T}_{\text {oil }}\right)$, geometrical parameters like journal bearing radius $\left(R_{j b}\right)$ and bearing length $\left(L_{j b}\right)$, oil film thickness $\left(h_{j b}\right)$ and a fitting parameter $k_{j b}$

$$
\dot{W}_{j b}=2 \pi R_{j b}^{3} k_{j b} \frac{L_{j b}}{h_{j b}} N^{2} \mu\left(\bar{T}_{o i l}\right)
$$

To the same extent, in the thrust bearing, friction losses may be expressed by the Equation 9, where $k_{t b}$ is a fitting factor, $R_{t b, \max }, R_{t b, \min }$ and $\bar{R}_{t b}$ are maximum, minimum and average radius of the Figure $2, \varphi$ is a geometrical parameter defined by the Equation 10 and $k_{m}$ denotes the fraction of lubricating oil passing through the considered bearing. Finally $F_{a t}$ is a term accounting the forces acting on the thrust bearing due to compressor and turbine pressure ratios difference. It is expressed by the Equation 11, referring to the Figure 3, where $p_{2}^{\prime}$ and $p_{3}^{\prime}$ are respectively pressures at the outlet of compressor wheel and at the inlet of turbine wheel and, in the previous equations, $A_{\text {comp }}^{\prime}$ and $A_{\text {turb }}^{\prime}$ are the effective areas of the compressor and turbine wheels.

$$
\begin{gathered}
\dot{W}_{t b}=k_{t b} \pi\left(R_{t b, \text { max }}^{2}-R_{t b, \text { min }}^{2}\right) \bar{R}_{t b}^{2} \sqrt[3]{\left|\frac{F_{a t \rho}}{12 k_{m} \dot{m} \varphi \mu\left(\bar{T}_{o i l}\right)}\right|} N^{2} \mu\left(\bar{T}_{o i l}\right) \\
\varphi=\frac{R_{t b, \text { max }}^{2}\left[\log \left(R_{t b, \max }\right)-0.5\right]}{2}-\frac{R_{t b, \text { min }}^{2}\left[\log \left(R_{t b, \min }\right)-0.5\right]}{2} \\
F_{a t}=\left|A_{\text {comp }}^{\prime} \frac{p_{1}-p_{2}}{4}-A_{t u r b}^{\prime} \frac{p_{3}^{\prime}-p_{4}}{2}\right|
\end{gathered}
$$




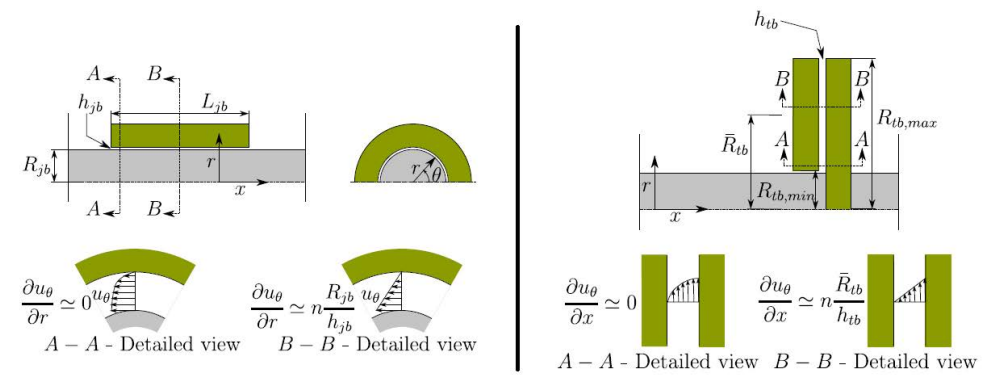

Figure 2. Simplified schemes of a journal bearings (left) and a thrust bearing (right).

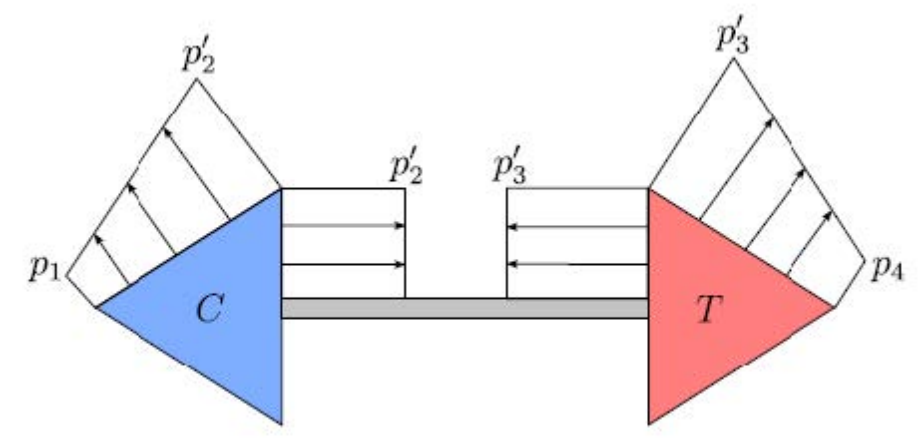

Figure 3. Schematic pressure distribution at the compressor and turbine wheels 
The 1D turbocharger models are mainly structured to perform simulations using adiabatic maps and efficiencies as a source term in order to account heat transfer effects turbine gasses and compressed air temperatures. However, it is not always possible to measure adiabatic maps and turbocharger manufacturers provide the maps usually non-adiabatic conditions. In order to face this problem, the present work shows a calculation procedure to obtain the adiabatic maps. The paper contains the following novel contributions:

- It presents an procedure for estimating the general heat transfer properties like conductive conductances and capacitances for the variety of turbochargers.

- It presents a in detail step by step procedure how to reverse the heat transfer relations between the fluids and turbocharger components by using the heat transfer and mechanical losses models precisely. Therefore it can calculate the adiabatic maps starting from a non-adiabatic maps. Figure 4 shows the overview of the calculation methodology to obtain the adiabatic efficiency from standard turbocharger maps.

- In order to perform the calculation, it is necessary to give some input parameters, geometrical data of the turbocharger and the reference conditions at which the corrected variables are calculated in the maps. Also, the ambient pressure during the measurement test and cooling water and lubricating oil mass flow and inlet temperatures should be known. If those parameters are unknown, some hypothesis is presented by assuming those parameter values. Besides, a sensibility analysis is shown to see the effect of each parameter in the final estimated adiabatic efficiency.

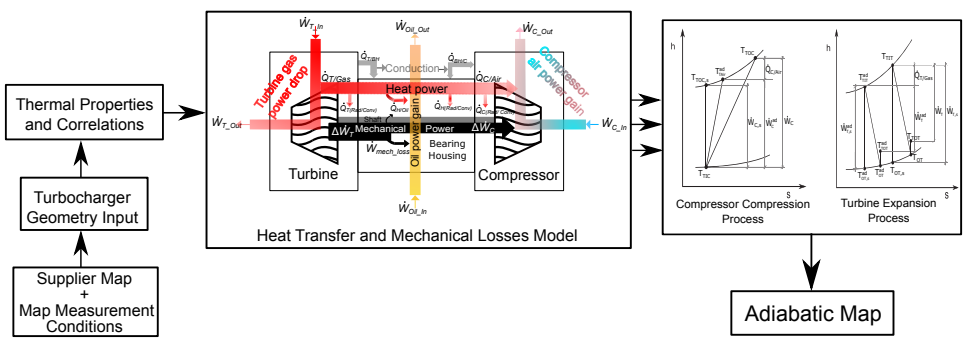

Figure 4. Overview of the calculation methodology to obtain the adiabatic efficiency

The first part of the paper concerns about the experiments that has been carried out in a gas stand with the two specific turbochargers. Then, a procedure for estimating the general heat transfer properties like conductive conductances and capacitances for the variety of turbochargers has been shown. The test data were used as a source data to the suggested thermal models by including new heat transfer properties; a computation method is shown to obtain the adiabatic maps from test data. 


\section{Test rig description}

The layout of the turbocharger gas stand used in this work has been shown in Figure $5^{16}$. The test bench is composed of the following parts:

- The mass flow to the turbine is provided by a two-stage compressor which has a maximum relative pressure of 5.30 bar, and its mass flow capacities range between 4400 and $7200 \mathrm{~m}^{3} / \mathrm{h}$. This compressor is of the oil-free type and has air cooler at each downstream (inter and after-cooler) and powered by a $450-\mathrm{kW}$ electric motor. On the line between the compressor and the combustion chamber, there are two settling tanks for the storage of compressed air and three-way bleeding valves for evacuation of any air to ambient.

- The mass flow is heated by a combustion chamber that is fueled by diesel. At the maximum mass flow rate, the system can attain a temperature of $1200 \mathrm{~K}$. This hot flow is conducted to the inlet of the turbine in the case of hot exposed and insulated tests.

- The amount of energy available at the turbine is controlled by the two-stage centrifugal compressor and the combustion chamber, both being key components of the gas stand.

- The turbocompressor takes air coming from the atmosphere. The air first passes through a filter, and then its flow rate is measured. An electronically driven back-pressure valve is present downstream the turbocompressor. From now on, turbocompressor will be referred as the compressor.

- The compressor and turbine inlet and outlet pipes have pressure and temperature sensors installed on them according to SAE J1826 ${ }^{17}$ and ${ }^{18}$ standards.

- The temperature (through a cooler and an electric heater), pressure (through a pressure control valve and an oil pump), and oil flow rate is controlled using an independent lubrication system. A Coriolis flow meter is used to measure the mass flow rate of the oil. The platinum resistance temperature detectors are used to measure inlet and outlet temperatures of the lubrication as they have low uncertainty. The independent lubrication system takes the periodic samples of oil with the aim of characterizing its properties such as specific heat capacity, density, and viscosity variations with temperature.

The representative information about the main sensors uncertainty and their measurement range is shown in Table 1 . The tests performed on this rig have been divided into two main groups, namely:

1. Quasi-adiabatic tests: In this kind of tests, heat transfer and mechanical losses are decoupled, which is the primary objective of the turbocharger under study. The heat transfer is minimized in this method, and the enthalpy variation in lubricating oil represents the turbocharger mechanical losses. The adjustment of the losses can be made by a physical model ${ }^{15}$. 


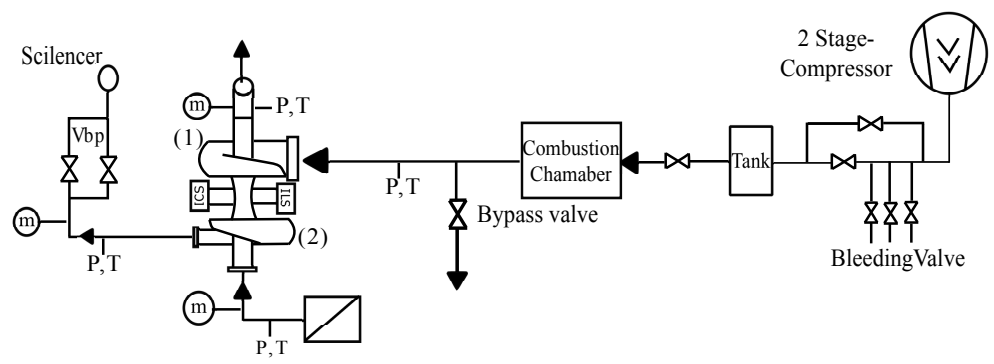

(1) Turbine, (2) Compressor, ICS-Independent cooling system ILS-Independent lubrication system, m-Mass flow Meter

T-Thermocouple, P-Pressure sensors, Vbp- Back-pressure valve

Figure 5. Schematic test bench and location of main sensors

16

2. Hot Test $^{9}$ : The primary objective in this kind of tests is to obtain the convective heat fluxes in a turbocharger. Besides, these tests can be divided into two groups:

(a) External Insulated Test: In this test, the complete turbocharger is insulated externally. So, the heat flow to an environment is minimized to a great extent, and the internal heat fluxes are allowed.

(b) Hot Exposed Test: The manufacturers usually perform this test to obtain the turbocharger maps. The main difference with the previous test is that the turbocharger is not insulated externally. Therefore the heat flows to the environment takes place. In heat transfer dedicated studies external heat flux are controlled by measuring surface emissivity and external cooling air flow velocity.

Table 1. Characteristics of sensors employed in the test bench

\begin{tabular}{ccc}
\hline Variable & Sensor & Range / Error \\
\hline Gas Pressure & Piezoresistive & {$[0-5] \pm 0.025 \mathrm{bar}$} \\
Air Pressure & Piezoresistive & {$[0-2] \pm 0.025 \mathrm{bar}$} \\
Gas and Air Temp. & K-type Therm. & $-200-+1200 \pm 2.2^{\circ} \mathrm{C}$ \\
Gas and Air Flow & Hot wire & {$[0-720] \pm 0.72 \mathrm{~kg} / \mathrm{s}$} \\
\hline Oil Pressure & Piezoresistive & {$[0-6] \pm 0.025 \mathrm{bar}$} \\
Oil Temperature & RTD & {$[-200-+650] \pm 0.15{ }^{\circ} \mathrm{C}$} \\
Oil Flow & Coriolis & {$[0-100] \mathrm{kgs}^{-1} \pm 0.1 \%$} \\
\hline
\end{tabular}

Table 2 shows the main characteristics of turbochargers used in this work and from that two turbochargers were selected to test them in gas stand. First, the hot exposed tests were performed on the selected turbochargers named as T\#4 (Diesel Turbocharger) and T\#8 (Petrol Turbocharger) under steady flow conditions. The operative conditions of the 
gas stand were set to obtain turbocharger maps at the highest turbine inlet temperature $\left(600^{\circ} \mathrm{C}\right.$ for $\mathrm{T} \# 4$ and $900^{\circ} \mathrm{C}$ for $\left.\mathrm{T} \# 8\right)$. Based on the thermal models which are proposed by $9,14,15$, a procedure to obtain the adiabatic maps from manufacturer maps (or) from hot exposed tests has been developed. To validate the adiabatization procedure proposed here tests under quasi-adiabatic conditions were performed on Turbocharger T\#4 in the gas stand. In these test, turbine inlet temperature, oil inlet temperatures, and compressor outlet temperatures are maintained as close as possible, and the turbocharger is thermally insulated from outside. The test method adopted to perform the quasi-adiabatic tests proved to be similar resulting in comparable characteristics curves as reported in ${ }^{15}$.

\section{General Correlations for Heat Transfer}

Thermal conductive conductance and capacitance are essential parameters to characterize the heat transfer model. This theoretical method to find heat transfer properties is necessary to use the lumped model further described in the section Adiabatic Maps Calculation and must provide all the capacitances and conductive conductances for each node. The theoretical development is based on the model described by Serrano et al. ${ }^{12}$, where the division of the turbocharger corresponds to the lumped model shown in Figure 1. It divides the turbocharger into different nodal planes, and after further simplification of turbocharger geometry, it is considered as a series of cylinders and cone frustum coupled together.

In the present paper, the model of Serrano et al. ${ }^{12}$ has been used for estimating the thermal capacitance of the turbocharger for each node. For estimating conductive conductances, a different approach has been considered. In this work, a precise definition for calculating the area with contact surface between the two metal nodes has been developed. Both models (capacitances and conductances) are fitted with a selected set of turbochargers, which have different external and rotor geometries, as shown in Table 2. The turbocharger T\#8 is used to check the ability of the correlations for predicting the capacitance and conductance. In the section Capacitance Modelling, a summary of capacitance modeling has been shown. Later the development of conductance modeling has been explained in section Conductive Conductance Modelling.

\section{Capacitance Modelling}

The capacitance of each node can be calculated from the product of the mass of the node and the specific heat capacity of the corresponding node, whose different material properties for each turbocharger component are listed in Table 3. When the information of the material is not available, the properties shown in Table 3 gives a good approximation of material properties.

The division of turbocharger into different nodes does not allow to use the below expression directly.

$$
C_{i}=m_{i} \cdot c_{i}=\rho \cdot V_{i} \cdot c_{i}
$$

As the central housing is divided into three nodes, and the contribution of different turbocharger components on some of the nodes is significant. So, Serrano et al. ${ }^{12}$ 
Table 2. Main characteristics of the used turbocharger

\begin{tabular}{|c|c|c|c|c|c|c|c|c|}
\hline Turbocharger\# & $\mathrm{T} \# 1$ & $\mathrm{~T} \# 2$ & $\mathrm{~T} \# 3$ & $\mathrm{~T} \# 4$ & $\mathrm{~T} \# 5$ & $\mathrm{~T} \# 6$ & $\mathrm{~T} \# 7$ & $\mathrm{~T} \# 8$ \\
\hline Turbocharger type & Diesel & Diesel & Diesel & Diesel & Petrol & Diesel & Petrol & Petrol \\
\hline $\begin{array}{l}\text { Turbine wheel diameter } \\
(\mathrm{mm})\end{array}$ & 41 & 37.5 & 35.5 & 41 & 37.5 & 39 & 31.5 & 52.8 \\
\hline $\begin{array}{l}\text { Compressor wheel diame- } \\
\text { ter }(\mathrm{mm})\end{array}$ & 49 & 46 & 44.5 & 49 & 40 & 49 & 37 & 62 \\
\hline VGT & Yes & Yes & Yes & Yes & No & Yes & No & No \\
\hline Water cooled & No & No & No & Yes & Yes & Yes & Yes & Yes \\
\hline $\begin{array}{l}\text { Turbine case external diam- } \\
\text { eter, } D_{T}(\mathrm{~mm})\end{array}$ & 121.7 & 122 & 100 & 110 & 80 & 110 & 85 & 120 \\
\hline $\begin{array}{l}\text { Housing external } \\
\text { diameter, } D_{H}(\mathrm{~mm})\end{array}$ & 54.5 & 70 & 50 & 60 & 57 & 60 & 70 & 90 \\
\hline $\begin{array}{l}\text { Compressor case external } \\
\text { diameter, } D_{C}(\mathrm{~mm})\end{array}$ & 125.8 & 123 & 110 & 125 & 104 & 115 & 110 & 147.7 \\
\hline $\begin{array}{l}\text { Turbine case external } \\
\text { length, } L_{T}(\mathrm{~mm})\end{array}$ & 73.8 & 70 & 50 & 70 & 30 & 75 & 30 & 49 \\
\hline $\begin{array}{l}\text { Housing case external } \\
\text { length, } L_{H}(\mathrm{~mm})\end{array}$ & 31.8 & 31 & 27 & 30 & 35 & 30 & 37 & 38 \\
\hline $\begin{array}{l}\text { Compressor case external } \\
\text { length, } L_{C}(\mathrm{~mm})\end{array}$ & 38.27 & 32 & 35 & 30 & 27 & 35 & 30 & 33 \\
\hline
\end{tabular}

Table 3. Turbocharger material properties

\begin{tabular}{ccccc}
\hline Parts & Material & $\begin{array}{c}\text { Specific Heat } \\
\left(\mathrm{JKg}^{-1} \mathrm{~K}^{-1}\right)\end{array}$ & $\begin{array}{c}\text { Density } \\
\left(\mathrm{Kgm}^{-3}\right)\end{array}$ & $\begin{array}{c}\text { Conductivity } \\
\left(\mathrm{Wm}^{-1} \mathrm{~K}^{-1}\right)\end{array}$ \\
\hline Turbine & SIMO Iron Casting & 510 & 7800 & 36 \\
Housing & FT200 Iran Casting & 525 & 7059 & 48.4 \\
Compressor & Aluminum & 860 & 2670 & 205 \\
\hline
\end{tabular}

assumed direct contribution from each node to other adjacent nodes. Equation 12 has been modified with some fitting constants $(\alpha, \beta, \gamma$ and $\epsilon)$ to use directly without any adjacent node contribution. The fitting constants are obtained with the selected turbochargers shown in Table 4, and the constraints of the constants have been chosen so that they should be neither more than unity nor less than zero. In the case of central node $\mathrm{H} 2$, to avoid zero contribution $\beta+\gamma$ must be less than one.

$$
\begin{aligned}
C_{T} & =\alpha \cdot m_{T} \cdot c_{T} \\
C_{H 1} & =(1-\alpha) \cdot m_{T} \cdot c_{T}+\beta \cdot m_{H} \cdot c_{H} \\
C_{H 2} & =(1-\beta-\gamma) \cdot m_{H} \cdot c_{H} \\
C_{H 3} & =(1-\epsilon) \cdot m_{C} \cdot c_{C}+\gamma \cdot m_{H} \cdot c_{H} \\
C_{C} & =\epsilon \cdot m_{C} \cdot c_{C}
\end{aligned}
$$




$$
\begin{array}{r}
0 \leq \alpha, \beta, \gamma, \epsilon \leq 1 \\
0<\beta+\gamma<1
\end{array}
$$

Aforementioned, turbocharger geometry is hard to acquire and sometimes it is not possible to calculate. So, to calculate the mass of each node a simplified method is applied as mentioned by Serrano et $\mathrm{al}^{12}$. This method has a few assumptions that need to be accepted. A cone frustum is considered for housing and cylinders for the turbine and compressor. To correct these simplifications three fitting constants are used. These fitting constants $\left(\theta_{i}\right)$ will take care of geometry because they are not solid cylinders and cone frustum, fluid is passing through the turbocharger.

$$
\begin{aligned}
& m_{H}=\theta_{H} \cdot \rho_{H} \cdot \frac{\pi}{12} \cdot L_{H} \cdot\left(D_{T}^{2}+D_{C}^{2}+D_{T} \cdot D_{C}\right) \\
& m_{T}=\theta_{T} \cdot \rho_{T} \cdot\left(\frac{\pi \cdot D_{T}^{2}}{4} \cdot L_{T}\right) \\
& m_{C}=\theta_{C} \cdot \rho_{C} \cdot\left(\frac{\pi \cdot D_{C}^{2}}{4} \cdot L_{C}\right)
\end{aligned}
$$

Summarizing, all the constants which are four for the capacitance $(\alpha, \beta, \gamma$ and $\epsilon)$ and three for the geometry $\left(\theta_{T}, \theta_{H}, \theta_{C}\right)$ are fitted with the experimental data of selected turbochargers which are obtained from an individual tests using incompressible flow in a special test rig called thermohydraulic test bench ${ }^{13}$. The non-linear regression technique was used to find out the unknown parameters, by minimizing the root mean square error between the measured and the modeled capacitance. Table 4 shows the fitting. Analyzing them one can generally conclude that turbine case mass has an influence of $30 \%$ in node $\mathrm{H} 1$ capacitance but bearing housing mass just $41 \%$. Also, that compressor mass does not have any influence in the capacitance of bearing housing node $\mathrm{H} 3$, being influenced just by the $36 \%$ of the bearing housing mass.

Table 4. Capacitance model fitting values

\begin{tabular}{cc}
\hline Coefficients & Estimation \\
\hline$\alpha$ & 0.6998 \\
$\beta$ & 0.4152 \\
$\gamma$ & 0.3652 \\
$\epsilon$ & 1 \\
$\theta_{T}$ & 0.7027 \\
$\theta_{H}$ & 0.4769 \\
$\theta_{C}$ & 0.6867 \\
\hline
\end{tabular}

Concerning the mass approximation, one can conclude that just about $48 \%$ of the mass of a cone frustum represents the bearing housing mass. Considering the uncertainties in 


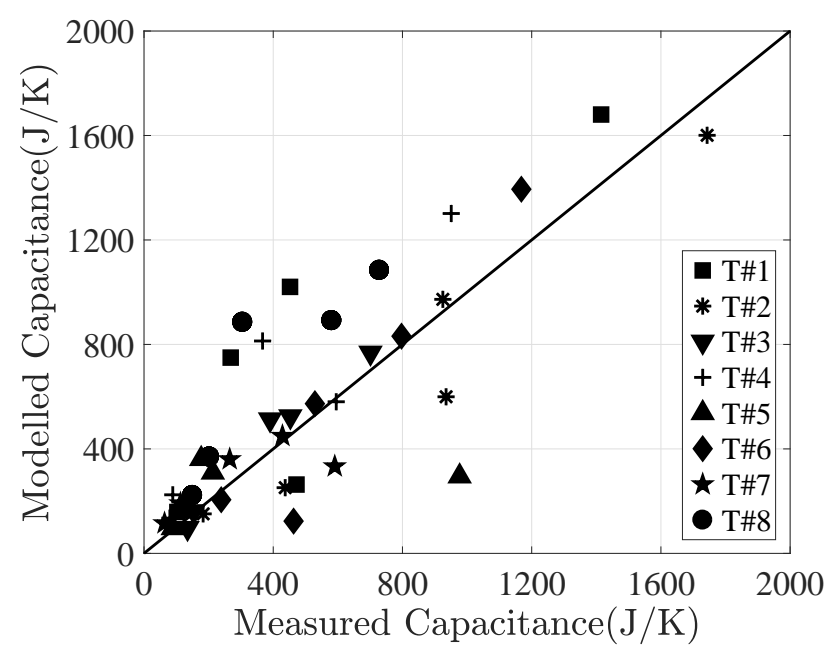

Figure 6. Capacitance fitting for different turbochargers

the experimental data and the inherent simplifications of equations 15; the agreement between modeled and measured data is acceptable as it can be observed in Figure 6 . Turbocharger T\#8 (circle points in Figure 6) is used for the validation of the capacitance model, and its data has not been used in the minimization procedure. The modeled capacitance of this turbocharger shows good accordance with measured values.

\section{Conductive Conductance Modelling}

The conductive conductance between two adjacent planes is a function of material conductivity, the width of each plane and a contact area between them ${ }^{12}$ as defined in equation 16.

$$
K_{i, j}=\frac{k_{i} \cdot k_{j}}{e_{i} \cdot k_{j}+e_{j} \cdot k_{i}} \cdot A_{i, j}
$$

For calculating the conductive conductance, it is necessary to know some information like material conductivity $\left(k_{i}\right.$ and $\left.k_{j}\right)$ at corresponding node, the equivalent width $\left(e_{i}\right.$ and $\left.e_{j}\right)$ between the planes and the contact area $\left(A_{i, j}\right)$. Table 3 shows the material conductivity of the turbocharger. The width of each plane is measured externally for turbine and compressor. As the housing is divided into three parts as shown in Figure 7 where the turbine and compressor casing corresponds to a node in the model. The fitting constants used for distributing the capacitance of housing nodes can be used for correct division of the housing length as shown in equation $17^{12}$. 


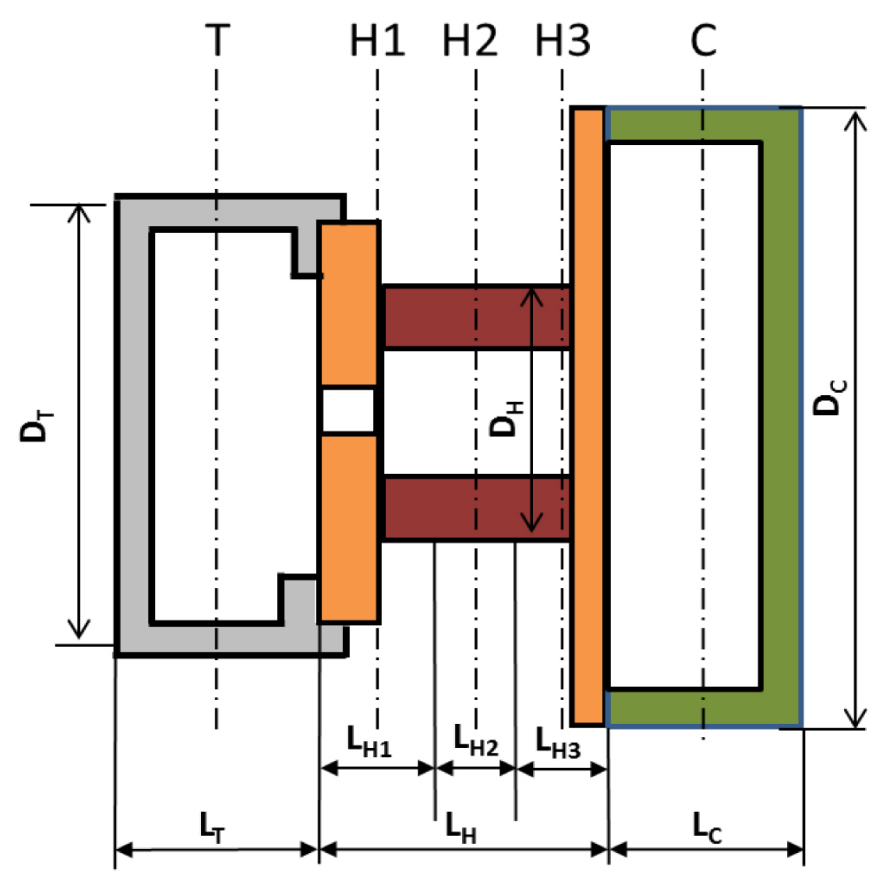

Figure 7. Simplification of turbocharger geometry ${ }^{16}$

$$
\begin{aligned}
& L_{H 1}=\beta \cdot L_{H} \\
& L_{H 2}=(1-\beta-\gamma) \cdot L_{H} \\
& L_{H 3}=\gamma \cdot L_{H}
\end{aligned}
$$

Finally, to find the conductive conductance from equation 16, the contact area between the planes is needed. It cannot be calculated directly from the external geometry values which are shown in Table 2. Due to the passages for the flow of different fluids inside the turbocharger do not allow the simplification of contact areas to circumference areas. To the assumption of cone frustum and cylinders for turbo parts, the effective area is considered as circumferential with the contact surface between the metal nodes as shown in equation 18.

$$
A_{e f f}^{i, j}=\pi \cdot\left(D_{e f f}^{i, j}-C_{s}^{i, j}\right) \times C_{s}^{i, j}
$$

As it is unable to measure the effective contact surface average diameter $\left(C_{s}\right)$ between the planes, a logarithmic expression with the average effective diameter between the two nodes has been considered by introducing two fitting constants.

$$
C_{s}^{i, j}=a_{i} \times \log \left(D_{e f f}^{i, j}\right)-b_{i}
$$


From the Table 2, it can be observed that the external geometries of different turbocharges are not so uniform and calculating the effective diameter with a linear approach is not feasible. However, the effective contact area of non-water cooled turbocharger should be different from those water cooled; this is due to the additional water passages inside the housing. Considering the details mentioned above the effective diameter is modeled based on the Gaussian distribution as shown equation 20, which has two fitting constants $\left(c_{i}\right.$ and $\left.d_{i}\right)$. By this, the effective diameter from smaller to bigger size turbochargers can be estimated.

$$
D_{e f f}^{i, j}=c_{i} \cdot e^{\left[-\left(\frac{D_{m}^{i, j}}{d_{i}}\right)^{2}\right]}
$$

The mean diameter $\left(D_{m}^{i, j}\right)$ is taken as the average diameter between the corresponding turbocharger external geometry (turbine, housing or compressor) as shown in equation 21.

$$
D_{m}^{i, j}=\frac{D_{i}+D_{j}}{2}
$$

For calculating the conductances $K_{T / H 1}$ and $K_{H 1 / H 2}$ the diameters of turbine and housing are involved, while for $K_{H 2 / H 3}$ and $K_{H 3 / C}$ the diameters of compressor and housing are used. Summarizing, four fitting constants $\left(a_{i}, b_{i}, c_{i}\right.$ and $\left.d_{i}\right)$ have been fitted for each conductive conductance, using an optimization tool that minimizes the root mean square difference between modeled and measured conductances. The obtained fitting constants for different conductance are shown in Table 5. Figure 8 shows the results of the fitting with acceptable accuracy. The model is also validated with the turbocharger T\#8 (non-filled and white points in Figure 8). The estimated conductance for this turbocharger shows good accordance with the measured values.

Table 5. Convective conductance model fitting values

\begin{tabular}{ccccc}
\hline Coefficients & $K_{T / H 1}$ & $K_{H 1 / H 2}$ & $K_{H 2 / H 3}$ & $K_{H 3 / C}$ \\
\hline$a_{i}$ & 6.030 & 1.300 & -0.041 & -0.164 \\
$b_{i}$ & 4.690 & 0.952 & -0.013 & -0.030 \\
$c_{i}$ & 4.933 & 2.079 & 1.367 & 1.201 \\
$d_{i}$ & 5.969 & 9.140 & 2.101 & 1.864 \\
\hline
\end{tabular}

\section{Adiabatic Maps Calculation}

Turbocharger adiabatic maps are a vital modeling tool since they only contain information about pure aerodynamic behavior (internal irreversibilities). The manufacturer maps at the time of measurement use SAE standards ${ }^{17,18}$ by including friction losses effects and heat transfer in their particular experiment. If using those maps in computational simulations, accurate results can be guaranteed when modeling similar conditions than those at which the turbocharger map was measured. Despite all that, it is hard to ensure 


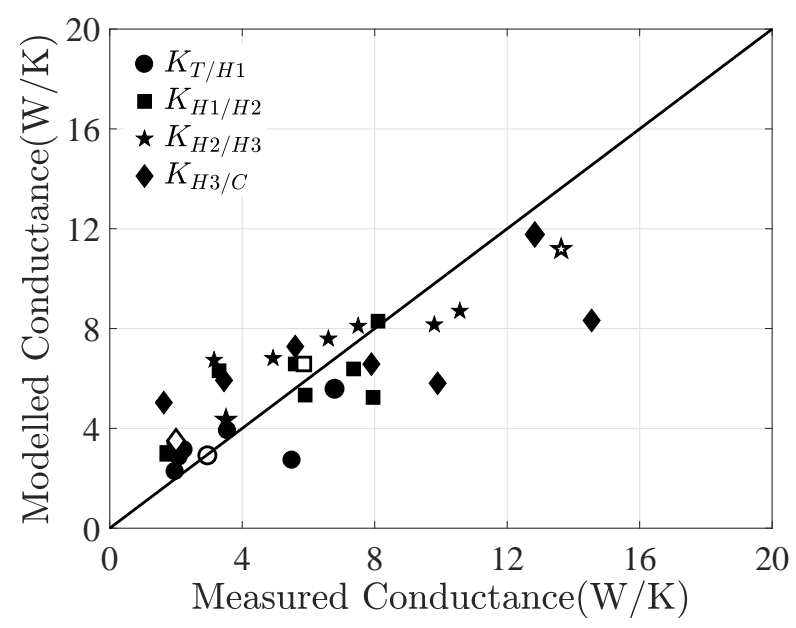

Figure 8. Conductive conductance fitting for different turbochargers (non-filled points corresponds to $\mathrm{T \# 8}$ )

all those conditions since the manufacturers do not provide many details about the measurement of those maps. Also, those maps provide reasonable results for turbocharger conditions where friction losses and heat transfer effects will be too low compared to turbocharger power (i.e., the points on the map which corresponds to high load). All those points are not a part of the engine homologation cycle's region. In partial load conditions of the engine, the friction losses and heat transfer effects are significant in comparison to the turbocharger power. In summary, to obtain an adiabatic map is necessary for the following reasons:

1. Bench-marking of maps from several manufacturers to check the highest level of aerodynamic efficiency.

2. Extrapolation of aerodynamic efficiency to non-measured pressure ratios for pulsating turbocharging operation due to exhaust gas unsteady flow.

3. Extrapolation to non-measured turbocharger speeds due to turbocharger accelerations and decelerations during dynamic cycles of the engine like the WLTC or those of RDE homologation.

Moreover, this is the only reason that in this paper the turbocharger heat transfer and friction losses models, which are already developed in previous works $9,14,15$ are used. These models as a tool are going to be useful in obtaining the adiabatic performance of the turbocharger manufacturer map by subtracting both heat transfer and friction losses effects. 


\section{Calculation Procedure}

The following procedure is proposed to obtain the turbine and compressor adiabatic maps with the help of manufacturer maps. The most critical assumption here is that turbine and compressor maps were measured together which is easy to do in turbocharger testing and commonly done in turbocharger division. In cases that the compressor and turbine maps may not have been measured together, the methodology described in the following section does not becomes invalid; it makes more challenging calculating actual isentropic efficiencies.

Although both maps must be measured simultaneously, the procedure for obtaining adiabatic turbine map is independent of that used to obtain the adiabatic compressor map and vice versa. However, both procedures are similar, and some information is shared.

\section{Input data}

Table 6 includes the list of parameters required to get the turbine and compressor adiabatic maps. In addition to the information provided by the manufacturer's maps, specific data is required. Most of this is quite essential to get accurate adiabatic maps. However, in some cases, those data are not available. The procedure presented in the section Step by step procedure assumes the availability of all data. Later, some hypothesis presented is to be used in a case that some parameters are not available. Besides, a sensibility analysis is shown to see the effect of each parameter in the final estimated adiabatic efficiency.

Table 6. List of required parameters to carry out the adiabatization process

\begin{tabular}{|c|c|c|}
\hline & Compressor & Turbine \\
\hline $\begin{array}{l}\text { Included } \\
\text { in } \\
\text { the map }\end{array}$ & $\begin{array}{l}\text {-Corrected speed }(\mathrm{rpm}) \\
\text {-Corrected mass flow }(\mathrm{kg} / \mathrm{s}) \\
\text {-Compression ratio }(-) \\
\text {-Efficiency (-) }\end{array}$ & $\begin{array}{l}\text {-Reduced speed }(\mathrm{rpm} / \sqrt{K}) \\
\text {-Reduced mass flow } \\
(\mathrm{kg} / \mathrm{s} \sqrt{K} / M P a) \\
\text {-Expansion ratio (-) } \\
\text {-Efficiency (-) }\end{array}$ \\
\hline $\begin{array}{l}\text { Aditional } \\
\text { Data }\end{array}$ & $\begin{array}{l}\text {-Turbine expansion ratio }(-) \\
\text {-Turbine efficiency (-) } \\
\text {-Total compressor inlet pressure } \\
(P a)\end{array}$ & $\begin{array}{l}\text {-Compressor compression } \\
\text { ratio(-) } \\
\text {-Compressor efficiency (-) } \\
\text {-Static turbine outlet pressure } \\
(\mathrm{Pa})\end{array}$ \\
\hline & $\begin{array}{l}\text {-Total turbine inlet temp } \\
\text {-Total compressor inlet } \\
\text {-Oil temperature }(\mathrm{K}) \\
\text {-Oil mass flow }(\mathrm{kg} / \mathrm{s}) \\
\text {-Coolant temperature }(\mathrm{K} \\
\text {-Coolant mass flow }(\mathrm{kg} \\
\text { Ambient temperature }(\mathrm{K}\end{array}$ & $\begin{array}{l}\text { rature }(K) \\
\text { mperature }(K)\end{array}$ \\
\hline
\end{tabular}


For the compressor map, reference pressure and a reference temperature $\left(p_{\text {ref }}\right.$ and $T_{\text {ref }}$ ) is also required for the definition of corrected speed and the corrected mass flow. The efficiency of the map is assumed to be the diabatic one, obtained from the temperatures as shown in equation 22 .

$$
\eta_{d i a b, C}=\frac{T_{T I C} \cdot\left(\Pi_{C}^{\frac{\gamma-1}{\gamma}}-1\right)}{T_{T O C}-T_{T I C}}
$$

On the other hand, the procedure also assumes that the turbine efficiency provided in the map is the Effective Turbine Efficiency (ETE), which is obtained comparing the compressor power and the isentropic turbine power as equation shows

$$
\eta_{E T E}=\frac{\dot{m}_{C} \cdot c_{p, C} \cdot\left(T_{T O C}-T_{T I C}\right)}{\dot{m}_{T} \cdot c_{p, T} \cdot T_{T G a s} \cdot\left(1-\Pi_{T}^{\frac{1-\gamma}{\gamma}}\right)}
$$

Finally, total to total pressure ratio is assumed to be present in the compressor map and total to static in the turbine map.

\section{Step by step procedure}

The followings steps must be followed for each point in the compressor and turbine maps.

Step 1 Getting the operating point from the map:

Turbine: The real mass flow through the turbine is calculated as:

$$
\dot{m}_{T}=\frac{\dot{m}_{T}^{r e d} \cdot p_{T I T}}{\sqrt{T_{T G a s}}}
$$

And the turbocharger speed as:

$$
N=N_{T}^{r e d} \cdot \sqrt{T_{T G a s}}
$$

The isentropic power and the real power can also be obtained using the map information.

$$
\begin{gathered}
\dot{W}_{T, s}=\dot{m}_{T} \cdot c_{p, T} \cdot T_{T G a s} \cdot\left(1-\Pi_{T}^{\frac{1-\gamma}{\gamma}}\right) \\
\dot{W}_{T}=\eta_{E T E} \cdot \dot{W}_{T, s}
\end{gathered}
$$

Compressor: Similar calculations can be performed to define the compressor operating point.

$$
\dot{m}_{C}=\frac{\dot{m}_{C}^{*} \cdot p_{T I C}}{\sqrt{T_{T I C}}} \cdot \frac{\sqrt{T_{r e f}}}{p_{\text {ref }}}
$$


And the turbocharger speed as:

$$
N=\frac{N_{C}^{*} \cdot \sqrt{T_{T I C}}}{\sqrt{T_{r e f}}}
$$

The isentropic power and the real power can also be obtained using the map information.

$$
\begin{gathered}
\dot{W}_{C, s}=\dot{m}_{C} \cdot c_{p, C} \cdot T_{T I C} \cdot\left(\Pi_{C}^{\frac{\gamma-1}{\gamma}}-1\right) \\
\dot{W}_{C}=\frac{\dot{W}_{C, s}}{\eta_{\text {diab }, C}}
\end{gathered}
$$

Step 2 Estimating the mass flow through the other turbomachinery.

Turbine: $\quad$ Assuming $\dot{W}_{C}=\dot{W}_{T}$ :

$$
\dot{m}_{C}=\frac{\eta_{d i a b, C} \cdot \dot{W}_{T}}{c_{p, C} \cdot T_{T I C} \cdot\left(\Pi_{C}^{\frac{\gamma-1}{\gamma}}-1\right)}
$$

Compressor: Using similar equal power assumption.

$$
\dot{m}_{T}=\frac{\dot{W}_{C}}{\eta_{E T E} \cdot c_{p, T} \cdot T_{T G a s} \cdot\left(1-\Pi_{T}^{\frac{1-\gamma}{\gamma}}\right)}
$$

Step 3 Total Compressor outlet temperature $\left(T_{T O C}\right)$ is calculated using equation 34 once compressor power $\left(\dot{W}_{C}\right)$ has been determined.

$$
T_{T O C}=T_{T I C}+\frac{\dot{W}_{C}}{\dot{m}_{C} \cdot c_{p}}
$$

Step 4 After the process of the diabatic compression, initial values have been assumed for air temperature (compressor diffuser total outlet temperature $\left.T_{T O D}\right)$. As the heat transfer effects are included in the compressor efficiency, compressor map cannot be used for obtaining that parameter directly. The calculation is initialized by choosing a variation of $\pm 10{ }^{\circ} \mathrm{C}$ around total outlet volute temperature of the compressor $\left(T_{T O C}\right)$. For high load points, compressed air will be at a higher temperature than compressor case, and so air will cool down from compressor diffuser to compressor volute outlet. The scenario is the opposite in case of the low load points. 
Step 5 Using the model proposed by ${ }^{15}$, initial mechanical losses $\left(\dot{W}_{m}\right)$ are estimated. The models need the application of the geometrical data from bearing and shaft of the turbocharger along with the turbocharger speed and oil conditions, i.e. mass flow and inlet temperature. The calculation of friction on the axial thrust also needs the compressor and turbine pressure ratio.

Step 6 As the mechanical losses $\left(\dot{W}_{m}\right)$ power is already calculated in Step 5, the first approximation of the oil outlet temperature $\left(T_{O O}\right)$ is calculated using equation 35 .

$$
T_{O O}=T_{O I}+\frac{\dot{W}_{m}}{\dot{m}_{O} \cdot c}
$$

Step 7 As it was discussed in ${ }^{9}$, there are four working fluids nodes named as Gas, Air, Oil and $W$. An initial set of nodes temperature has been selected $(\mathrm{n}=0)$. The exhaust gases that enter the turbine is referred to the node Gas, and that node is characterized by measured inlet temperature of the turbine $\left(T_{T \text { Gas }}\right)$. The adiabatically compressed air at the outlet diffuser of the compressor $\left(T_{T A i r}\right)$ is called node Air while nodes $O i l$ and $W$ are characterized by lube oil $\left(T_{O I}\right)$ and coolant liquid $\operatorname{inlet}\left(T_{W I}\right)$. There are five metal nodes named as $T, H 1, H 2, H 3$ and $C$. Additionally, one node is introduced inside the lubricating oil to take care of the heat transfer and mechanical losses effects named as $O H 2$, as it is shown in Figure 1. Values showed in Table 7 have been chosen as initial values for nodes temperature. Lubricating oil outlet temperature ( $T_{O O}$ ) estimated in Step 6, equation 35, has been chosen as the initial temperature for node $\mathrm{OH} 2$.

Step 8 Iterative process begins.

In equation 36, the vector of nodes temperature is shown which is built from the values obtained in Step 7. In equation 37, Conductance Matrix $K_{s}$ is shown which uses the heat transfer correlations which are already developed in the previous work for internal convections and external heat losses in the turbocharger ${ }^{9,14}$. For conductive conductances, the model developed in section 3 is used.

Table 7. Initial nodes temperature $(n=0)$

\begin{tabular}{cccc}
\hline \multicolumn{2}{c}{ Fluid Nodes } & & Metal Nodes \\
\hline node & initial value & node & initial value \\
$T_{\text {Gas }}$ & $T_{T G a s}$ & $T_{T}$ & $0.8 \cdot\left(T_{T \text { Gas }}-T_{T I C}\right)+T_{T I C}$ \\
$T_{A i r}$ & $T_{T O C}$ & $T_{H 1}$ & $0.5 \cdot\left(T_{T \text { Gas }}-T_{T I C}\right)+T_{T I C}$ \\
$T_{O i l}$ & $T_{O I}$ & $T_{H 2}$ & $0.3 \cdot\left(T_{T \text { Gas }}-T_{T I C}\right)+T_{T I C}$ \\
$T_{O H 2}$ & $T_{O O}$ & $T_{H 3}$ & $0.2 \cdot\left(T_{T \text { Gas }}-T_{T I C}\right)+T_{T I C}$ \\
$T_{W}$ & $T_{W I}$ & $T_{C}$ & $0.1 \cdot\left(T_{T \text { Gas }}-T_{T I C}\right)+T_{T I C}$ \\
\hline
\end{tabular}




$$
\begin{gathered}
\mathbf{T}_{N}^{n}=\left[\begin{array}{cccccccccc}
T_{G a s} & T_{T O C} & T_{O I} & T_{W I} & T_{T} & T_{H 1} & T_{H 2} & T_{H 3} & T_{C} & T_{O H 2} \\
\text { (36) }
\end{array}\right]^{t} \\
\mathbf{K}_{\mathbf{s}}=\left(\begin{array}{cccccccccc}
1 & 0 & 0 & 0 & 0 & 0 & 0 & 0 & 0 & 0 \\
0 & 1 & 0 & 0 & 0 & 0 & 0 & 0 & 0 & 0 \\
0 & 0 & 1 & 0 & 0 & 0 & 0 & 0 & 0 & 0 \\
0 & 0 & 0 & 1 & 0 & 0 & 0 & 0 & 0 & 0 \\
K_{T / G a s} & 0 & 0 & 0 & K_{T / T} & K_{T / H 1} & 0 & 0 & 0 & 0 \\
0 & 0 & 0 & 0 & K_{H 1 / T} & K_{H 1 / H 1} & K_{H 1 / H 2} & 0 & 0 & 0 \\
0 & 0 & 0 & K_{H 2 / W} & 0 & K_{H 2 / H 1} & K_{H 2 / H 2} & K_{H 2 / H 3} & 0 & K_{H 2 / O H 2} \\
0 & 0 & 0 & 0 & 0 & 0 & K_{H 3 / H 2} & K_{H 3 / H 3} & K_{H 3 / C} & 0 \\
0 & K_{C / A i r} & 0 & 0 & 0 & 0 & 0 & K_{C / H 3} & K_{C / C} & 0 \\
0 & 0 & 0 & 0 & 0 & 0 & 0 & 0 & 1
\end{array}\right)
\end{gathered}
$$

Step 9 With the application of heat transfer model, nodes temperatures are calculated. Thus, after solving equation 38, equation 39 is used to calculate the vector of input temperatures.

$$
\begin{aligned}
& \mathbf{T}_{N}^{n+1}=\mathbf{K}_{s}^{-1} \cdot \mathbf{T}_{l} \\
& \mathbf{T}_{l}=\left[\begin{array}{llllllllll}
T_{T G a s} & T_{T A i r} & T_{O I} & T_{W I} & 0 & 0 & 0 & 0 & 0 & T_{O H 2}
\end{array}\right]^{t}
\end{aligned}
$$

Step 10 The calculation of temperature differences between model nodes is done using equation 40. The calculation of heat fluxes is done using equation 41 .

$$
\begin{gathered}
\Delta \mathbf{T}(\mathbf{i}, \mathbf{j})=\mathbf{T}_{N}^{n+1}(i)-\mathbf{T}_{N}^{n+1}(j) \\
\dot{Q}(i, j)=\mathbf{K}_{\mathbf{s}} \cdot \Delta \mathbf{T}(\mathbf{i}, \mathbf{j})
\end{gathered}
$$

Heat fluxes are considered positive when heat flows from the fluid to the metal node.

Step 11 Expression 42 can be used for the determination of the adiabatic total inlet temperature of the turbine $\left(T_{\text {TGas }}^{a d}\right)$ after subtracting the heat transfer that takes place on the turbine side.

$$
T_{T G a s}^{a d}=T_{G a s}-\frac{\dot{Q}_{T / G a s}}{\dot{m}_{T} \cdot c_{p, T}}
$$

For the compressor side, equation 43 provides the adiabatic temperature at the outlet. 


$$
T_{\text {TAir }}^{a d}=T_{T O C}+\frac{\dot{Q}_{C / A i r}}{\dot{m}_{C} \cdot c_{p, C}}
$$

Where $T_{T O C}$ is obtained form equation 22.

Step 12 Using equation 43 the adiabatic compressor outlet temperature is obtained, therefor the current compressor mechanical power after adiabatic compression process $\left(\dot{W}_{C}^{a d}\right)$ can be determined by equation 44 .

$$
\dot{W}_{C}^{a d}=\dot{m}_{C} \cdot c_{p, C} \cdot\left(T_{T O C}^{a d}-T_{T I C}\right)
$$

Thus, considering mechanical losses in the shaft $\left(\dot{W}_{m}\right)$ the current adiabatic mechanical power in the turbine can be obtained by equation 45

$$
\dot{W}_{T}^{a d}=\dot{W}_{C}^{a d}+\dot{W}_{m}
$$

Step 13 Temperature for oil node can be calculated using mechanical losses model $\left(\dot{W}_{m}\right)$, oil inlet temperature, and heat fluxes that are obtained in Step 10.

For oil node $\mathrm{OH} 2$, the temperature is calculated by adding the mechanical power due to friction losses $\left(\dot{W}_{m}\right)$ to the oil inlet conditions $\left(T_{O I}\right)$ as shown in equation 46. Once that temperature has been determined, the proposed thermal model by ${ }^{9}$ shows that heat flux $\dot{Q}_{H 2 / O i l}$ is received by the lubricating oil that raises its temperature from $\mathrm{T}_{\mathrm{OH} 2}$ conditions to outlet oil port temperature, i.e. $T_{O O}$ as indicated in equation 47 . The heat flux $\dot{Q}_{H 2 / O i l}$ is divided by 2 in the equation 47 , as in the proposed thermal model by ${ }^{9}$, shows that oil exchanges the heat with central housing node $H 2$ and from the average oil temperature between outlet $\left(T_{O O}\right)$ and node $\mathrm{T}_{\mathrm{OH} 2}$ as shown in Figure 9.

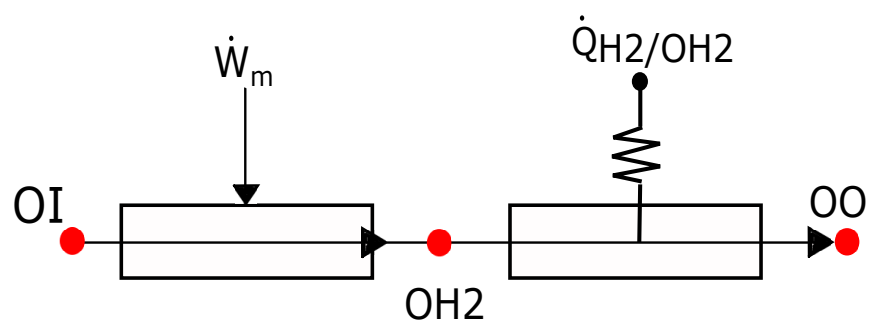

Figure 9. Heat fluxes to the lubricating oil

$$
T_{O H 2}=T_{O I}+\frac{\dot{W}_{m}}{\dot{m}_{O} \cdot c_{O I L}}
$$




$$
T_{O O}=T_{O H 2}+\frac{\frac{\dot{Q}_{H 2 / O H 2}}{2}}{\dot{m}_{O} \cdot c_{O I L}}
$$

Step 14 New temperatures for compressor outlet diffuser $\left(T_{T A i r}^{a d}\right)$, obtained by equation 43 , turbine outlet $\left(T_{T O T}^{a d}\right)$, obtained by equation 48 and the lubricating outlet oil $\left(T_{O O}\right)$, which is calculated by equation 47 , are compared with calculations from previous iteration. In case of a bigger difference than a defined tolerance is obtained, the solver is feedback to step Step 8. In other cases, the process continues with the next step.

$$
T_{T O T}^{a d}=T_{T G a s}^{a d}+\frac{\dot{W}_{T}^{a d}}{\dot{m}_{T} \cdot c_{p, T}}
$$

Step 15 Only for the turbine side, a new isentropic enthalpy drop must be calculated. Considering the same pressure drop but using the new adiabatic turbine inlet temperature, the new isentropic outlet temperature can be determined by equation 49 . With this temperature, the isentropic power in the turbine can be calculated by equation 50

$$
\begin{gathered}
T_{O T, s}=T_{T G a s}^{a d} \cdot\left(1-\Pi_{T}^{\frac{1-\gamma}{\gamma}}\right) \\
\dot{W}_{T, s}^{a d}=\dot{m}_{T} \cdot c_{p}\left(T_{T G a s}^{a d}-T_{O T, s}\right)
\end{gathered}
$$

Step 16 After the determination of the adiabatic and isentropic powers of the turbine and compressor, the description of the adiabatic efficiency is quite simple, which was the objective of this solver. Once the process has converged, adiabatic efficiency for the turbine or the compressor can be obtained from 51 and 52.

Turbine: Assuming $\dot{W}_{C}=\dot{W}_{T}$ :

$$
\eta_{T}^{a d}=\frac{\dot{W}_{T}^{a d}}{\dot{W}_{T, s}^{a d}}
$$

Compressor: Using similar equal power assumption.

$$
\eta_{C}^{a d}=\frac{\dot{W}_{C, s}}{\dot{W}_{C}^{a d}}
$$

The above step by step calculation procedure is outlined in Figure 10 to give the overview of an procedure to obtain the adiabatic maps. 


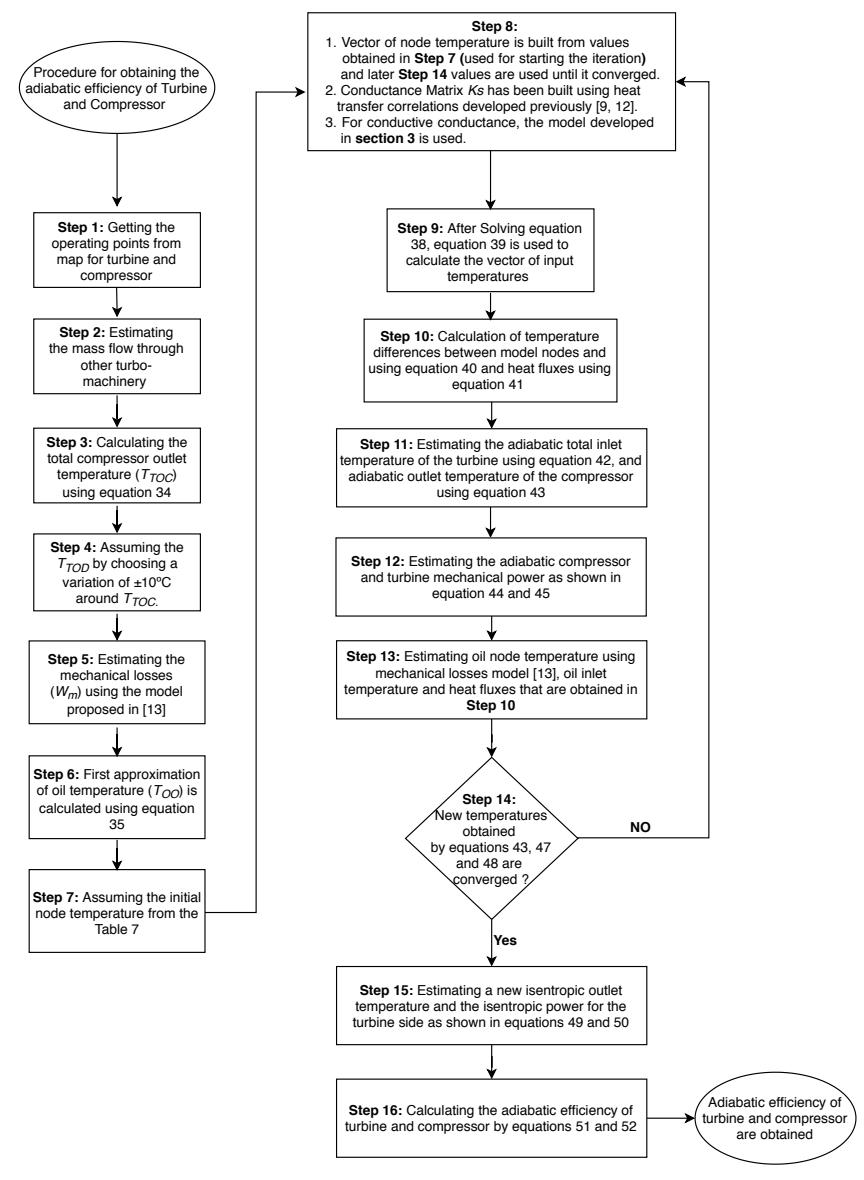

Figure 10. Calculation Procedure

Main assumptions for not available information:

The procedure presented to get adiabatic turbine and compressor maps requires a significant quantity of data. Unfortunately the maps from turbocharger manufacturers, most of the time measured using SAE standards ${ }^{17,18}$, and do not include all of this required information. However, the previously described procedure still can be used to obtain approximated adiabatic maps by making some assumptions listed below for nonavailable data. 
- Some of the required parameters are the inlet temperature of the different fluids. For the turbine inlet, if the turbocharger was measured in hot conditions, $T_{\text {Gas }}$ could be assumed to be $600^{\circ} \mathrm{C}$ in diesel and $900^{\circ} \mathrm{C}$ in petrol engine turbochargers, which is the usual practice of measuring turbocompressor map. For the compressor $\left(T_{\text {Air }}\right)$, ambient temperature could be assumed. Oil and water (if water cooled) temperature are also very important in the procedure. In this case, an averagevalued could be used for all points of the map.

- The pressure ratio of the other turbo-machine is another required parameter. If this information is not available, it could be assumed that both pressure ratios are similar. This is a usual practice which is followed to avoid high thrust loads.

- It could also be assumed that the outlet pressure of the turbine and inlet pressure of the compressor is the ambient pressure which is the standard practice. Thus, the inlet pressure of the turbine becomes equal to the ambient pressure times the expansion ratio $\left(\Pi_{T}\right)$, and the outlet pressure of the compressor becomes equal to the ambient pressure times the compression ratio $\left(\Pi_{C}\right)$

- The diabatic efficiency of the other turbo-machine is also required. If this information is not available for every tested point, a turbocharger efficiency can choose in between $35 \%$ to $45 \%$. Turbocharger efficiency is the product of compressor diabatic efficiency times ETE. Therefore, if ETE is known, because we are processing the turbine map into adiabatic conditions, then compressor diabatic efficiency can be calculated as 0.45 divided by ETE; and vice-versa if diabatic compressor efficiency is the only information available because we are processing the compressor map into adiabatic.

- As the mass flow of the coolant and lubricant is essential for calculation. If this information is not available from the turbocharger manufacturer hot tests, then the typical values of oil and coolant from the engine can be used.

- If the external heat transfer has to be considered. The heat transfer model of the turbocharger has to include correlations of heat transfer for convection and external radiation ${ }^{9,14}$. In the example used at present work, the turbocharger was thermally insulated from outside during testing in gas stand which minimized these external heat losses.

A sensibility study has been performed on turbocharger T\#8 to check the validity of the hypothesis proposed. The procedure has been used to get the adiabatic compressor and turbine map of a turbocharger where all required information is available. The procedure has also been used by changing the value of those parameters that are not included in the map data. The parameters that have been modified are listed below:

- Pressure ratio in the other turbo-machinery: $\pm 20 \%$

- Efficiency of the other turbo-machinery: \pm 10 percent points. 
- Compressor inlet temperature: $\pm 20 K$

- Turbine inlet temperature: $\pm 100 \mathrm{~K}$

- Oil temperature: $\pm 20 K$

- Coolant temperature: $\pm 20 K$

- Ambient temperature: $\pm 20 K$

- Oil mass flow: $\pm 20 \%$

- Coolant mass flow: $\pm 20 \%$

The results are compared with the adiabatic efficiency obtained using the correct values of all parameters. The difference for all point in the maps, in percent points, is represented versus the expansion ratio (turbine) or the compression ratio (compressor). Figures 11 and 12 provide an overview of the effect of errors in the input data on the final result.
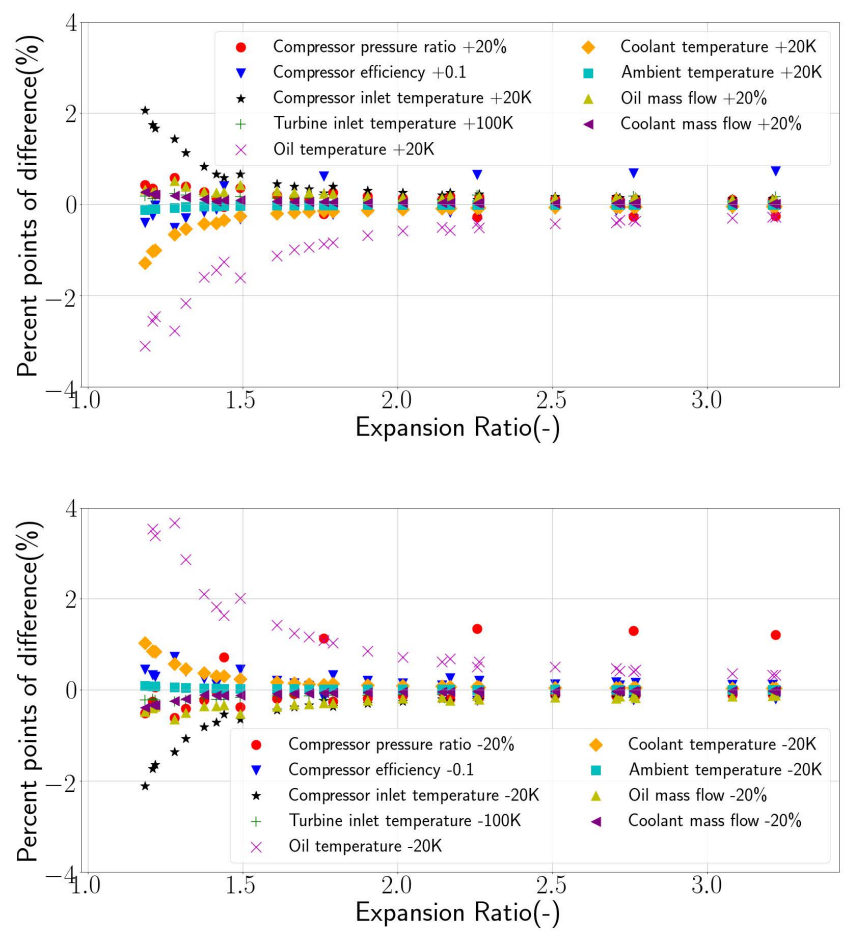

Figure 11. Effect of input data in adiabatic turbine efficiency 

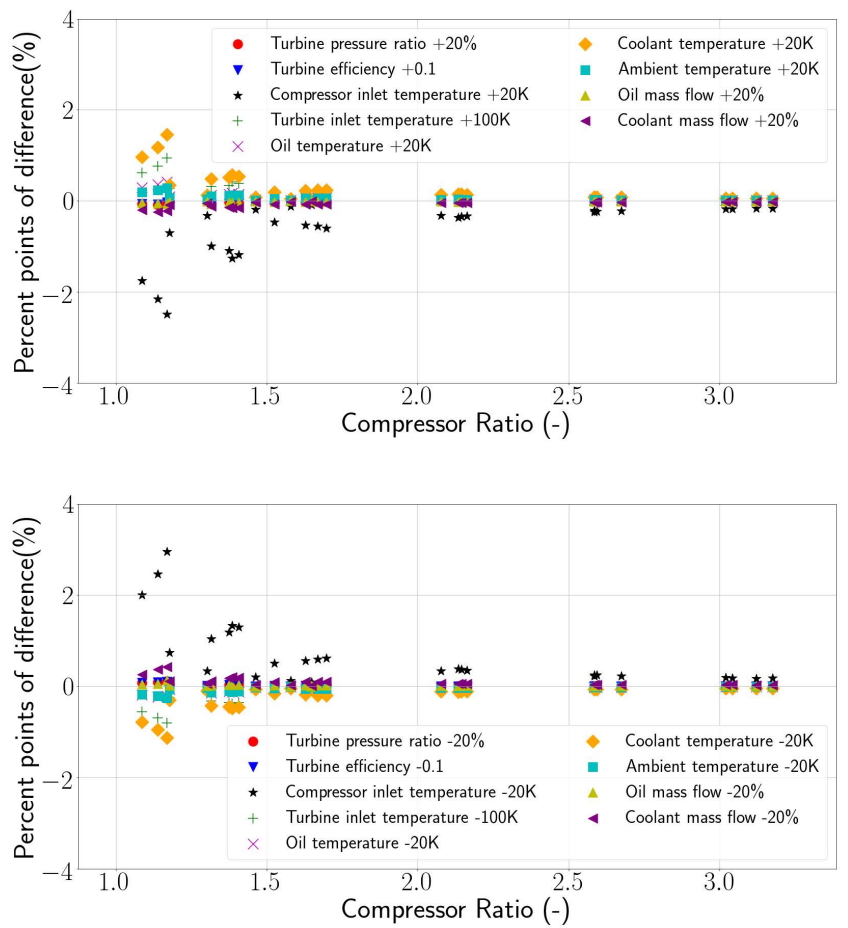

Figure 12. Effect of input data in adiabatic compressor efficiency

From the Figures 11 and 12, the following conclusions can be obtained.

- The most critical parameters are the inlet temperature of the different fluids (gas in the turbine, the air in the compressor, oil, and coolant). Compressor inlet temperature and oil inlet can produce an error of 3 percent points. It is true that an error of $20 \mathrm{~K}$ in the input data is very high, but sometimes the information is unavailable, and one must guess. So the worst case has been considered to show the impact.

- Oil and coolant mass flow do not cause significant error in predicted adiabatic efficiency even changing them $20 \%$ versus real value.

- Ambient temperature does not affect the output significantly, even though the turbocharger was measured in exposed conditions.

- The effect of the efficiency of the other turbomachinery on the final results is minimal.

- The pressure ratio of the other turbomachinery only produces significant differences when adiabatic turbine efficiency is being calculated, as shown in 
Figure 11. When the adiabatic compressor efficiency has calculated the errors in turbine efficiency assuming has little influence, Figure 12. Anyhow the errors in the turbine case are most of the time below 1 percent point.

- Depending on the compressor operating point, the heat flow goes from the metal to the air or from the air to the metal. In general, for low compression ratio the air temperature can be lower than the metal one, but for high compression ratio, the contrary occurs.

Furthermore, a sensibility study is also performed on the same turbocharger T\#8 in the case of diabatic efficiency of other turbo-machine is not available. The study has been performed by assuming the turbocharger efficiency as 35\% in one case and $45 \%$ in the other case. This is done to check the level of accuracy that the model can able to produce the adiabatic map with the assumed turbocharger efficiency values. The results are compared with the adiabatic efficiency obtained using the correct values of all parameters. Figure 13 shows the effect of using the average turbocharger efficiency for two cases (35\% and 45\%) to obtain the compressor and turbine adiabatic efficiency. At low expansion or compression ratios, by using the efficiency value of $35 \%$ the errors are in positive and by using the efficiency value of $45 \%$ the errors are in negative side. In both the cases error produce by model is not more than 0.4 percent points. From the Figure 13 it can be concluded that the assumption of $45 \%$ and $35 \%$ as turbocharger efficiency does not affect the results in larger errors.

\section{Application Example}

In this section, proposed methodology to obtain adiabatic maps from standard manufacturer ones has been applied to the turbochargers ( $\mathrm{T \# 4}$ and $\mathrm{T \# 8}$ ) which are tested in the gas stand with high turbine inlet temperatures as mentioned before. The procedure is also validated with turbocharger $\mathrm{T} \# 4$ which was also tested in quasi-adiabatic conditions to obtain an adiabatic efficiency of the turbomachinery (aerodynamic efficiency). The oil lubricating and coolant conditions were recorded during characterization of the turbocharger, and it was not necessary to make any assumption. Additionally, the recording of the turbine and compressor parameters was done at the same time and hence, the assumptions for pressure or mass flow were not needed.

\section{Compressor Adiabatic Maps}

Figure 14 and Figure 15 show the compressor efficiency for hot flow tests that have been performed on turbocharger $\mathrm{T} \# 4$ and $\mathrm{T} \# 8$ respectively. The compressor efficiency here has been defined as a ratio of power between isentropic compression process $\left(\dot{W}_{C, s}\right)$ and real process $\left(\dot{W}_{C}\right)$. The real process can only account for pure aerodynamic effects in the case of adiabatic tests, or heat transfer for hot tests can influence them. Heat transfer and mechanical losses models ${ }^{9,14,15}$ have been applied to the hot measurements to discount those effects from measured compressor power. Thus using equation 44 , the 

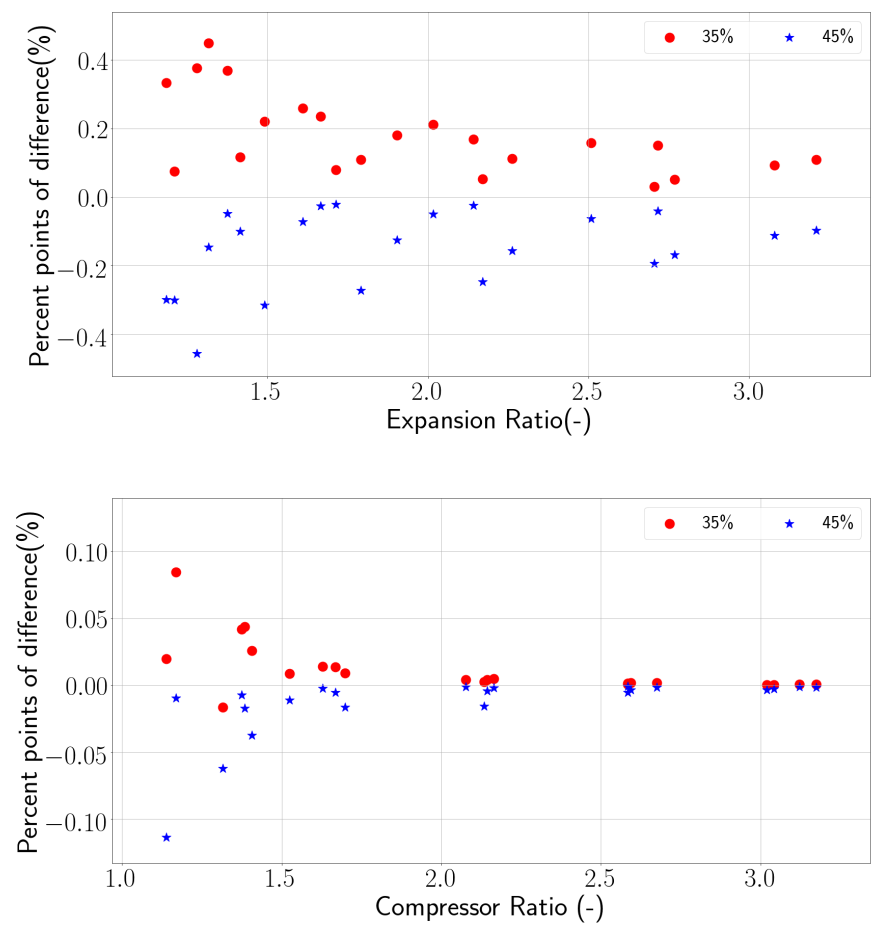

Figure 13. Effect of using the average turbocharger efficiency to obtain turbine and compressor adiabatic efficiency

power for the adiabatic compression process $\left(\dot{W}_{C}^{a d}\right)$ is calculated which is the adiabatic compression efficiency already defined in equation 52 . The procedure which is shown in the previous section to obtain adiabatic efficiency using hot tests is named as adiabatized. That efficiency must agree with the compressor efficiency from almost-adiabatic tests. Immeasurable results are shown in Figure 14, and there is a small discrepancy that appears between both the magnitudes since model correlations have been used for the determination of the adiabatic efficiency (adiabatized). It is due to this reason only that significant errors in the prediction of mechanical losses and heat transfer are changed into calculation efficiency of the compressor. At lower turbo speeds, the valid results are obtained as these are the points where the effects of heat transfer are the most notable.

The compressor efficiency compares the adiabatized compressor efficiency from a hot test with compressor adiabatic efficiency obtained from an almost-adiabatic test for turbocharger T\#4. As shown in Figure 14, the differences in compressor efficiency (from an adibatized and almost-adiabatic test (cold)) are found to be significantly lower (with RMSE of 0.0121 from lower to higher turbo speeds) than the discrepancies between compressor efficiency defined from the hot test and adiabatic efficiency calculated from 
49 krpm
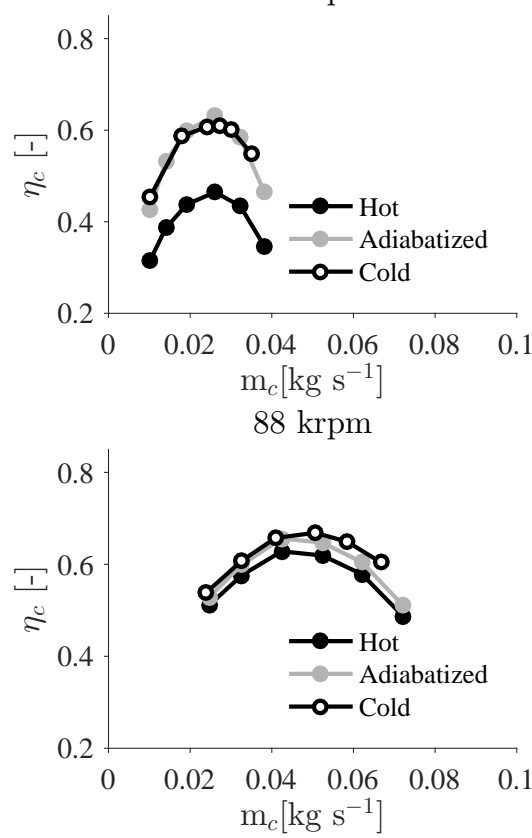

69 krpm
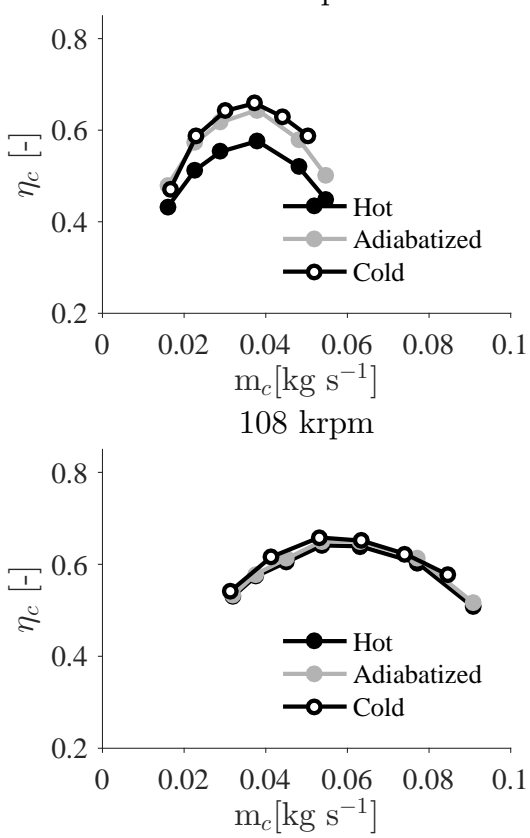

Figure 14. Comparison of compressor efficiencies from almost-adiabatic tests (represented as 'Cold'), hot tests, and proposed methodology for T\#4

an almost-adiabatic test. With an increase in the load and speed of the compressor, fewer discrepancies are observed between hot defined and adiabatic efficiency. That is due to the less importance of heat transfer and mechanical friction losses power with an increase in load as compared to turbocharger power ${ }^{9}$. Figure 14 also shows that at high turbocharger speeds of $108 \mathrm{krpm}$ or above, compressor efficiency determined from the hot test could be used instead of using adiabatic efficiency. Thus, it can be concluded that compressor efficiency showed in manufacturer maps (defined with a hot test on the turbine side) provides reasonable results for high turbocharger speeds only. In case of low turbocharger speeds (which happens corresponds to low engine loads and speeds), it is obligatory to use heat transfer models, so that heat transfer effects are discounted from hot measurements. It is vital since the efficiency of a compressor which is characterized in that way is highly different from adiabatic compressor efficiency.

The procedure also applied to one of the petrol turbocharger T\#8 was tested in a hot gas stand with high turbine inlet temperatures around $900^{\circ} \mathrm{C}$. The proposed methodology is used to obtain the adiabatic maps. Figure 15 shows the comparison of compressor efficiency from the hot test and with adiabatization method. The inconsistencies in compressor efficiency are repeatedly notable only at the lowest turbocharger speeds. 
Therefore the adiabatized efficiency with the proposed methodology is higher mainly at the lower speeds. For this turbocharger (T\#8), the bearing housing was cooled with water at $50^{\circ} \mathrm{C}$ while testing in hot conditions. Figure 15 shows that, even with so active water cooling, measured maps in hot conditions do not represent the aerodynamic efficiency of the machine correctly at low speeds. At the high speeds, the heat transfer effects on the compressor outlet temperature are almost negligible in comparison to compressor mechanical power, and this explains the almost insignificant differences in efficiency at higher turbocharger speeds.
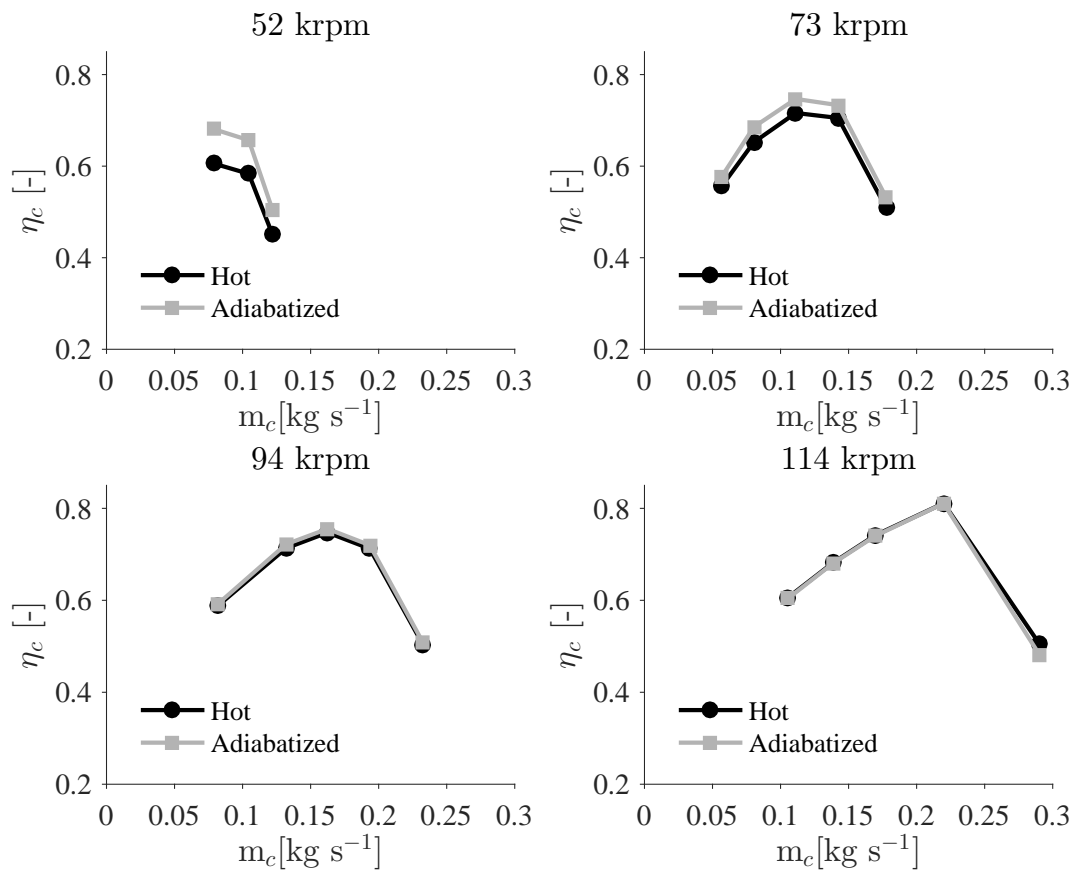

Figure 15. Comparison of compressor efficiencies from hot tests and proposed methodology adiabatization for $\mathrm{T \# 8}$

\section{Turbine Adiabatic Maps}

Figure 16 shows the turbine efficiency calculated from an almost-adiabatic test and hot steady test versus blade speed ratio. Equation 53 shows the traditional way to calculate the effective turbine efficiency (ETE) based on the ratio between the compressor delivered power and turbine isentropic power. Equation 53 is used in the calculation of ETE from the hot steady test, and it is represented as 'Hot' in Figure 16 as hot. This definition commonly used in turbine maps provided by the turbocharger manufacturers. 

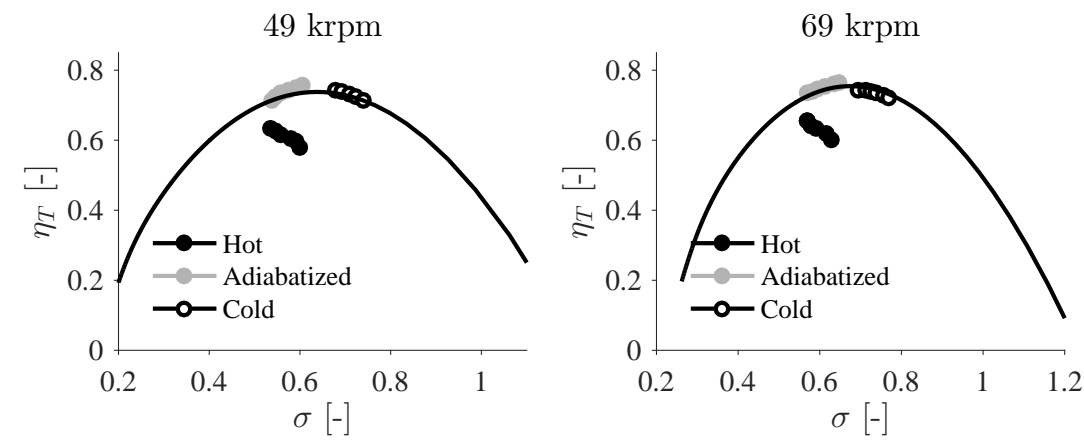

$88 \mathrm{krpm}$
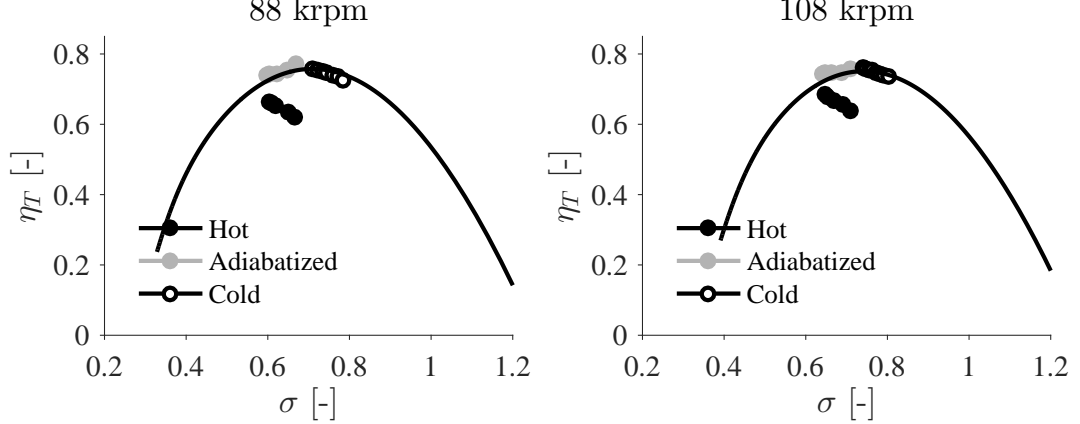

Figure 16. Comparison of turbine efficiencies from almost-adiabatic tests (represented as 'Cold'), hot tests, proposed methodology and extrapolation from adiabatic tests for T\#4

It is important to note that the definition ETE in equation 53 uses the diabatic turbine isentropic power $\left(\dot{W}_{T, s}\right)$ instead of adiabatic turbine isentropic power $\left(\dot{W}_{T, s}^{a d}\right)$. As it is unknown without the heat transfer as shown in Figure 1. The efficiency calculated with this definition includes the mechanical friction losses power, as the actual turbine power is not directly measured, as it is affected by the heat transfer. The compressor power is evaluated using its mass flow rate, mean specific heat capacity, and inlet and outlet temperatures, but without deducting the compressor heat flow. As a result, from hot steady tests, the efficiency is lower by combining all the effects.

$$
\eta_{T \text { map }}=\frac{\left(T_{T O C}-T_{T I C}\right) \cdot c_{p, C} \cdot \dot{m}_{C}}{\left(T_{T G a s}-T_{O T, s}\right) \cdot c_{p, T} \cdot \dot{m}_{T}}=\frac{\dot{W}_{C}^{a d}+\dot{Q}_{C / A i r}}{\dot{W}_{T, s}}=E T E
$$

In the turbocharger, there are complex interactions among different energy fluxes. The effective turbine efficiency showed on the standard maps is a mixture of all the different effects. So, equation 53 is further derived based on the Enthalpy-Entropy chart of Turbine and compressor for an adiabatic and non-adiabatic process as shown in Figure 1; where the compressor mechanical power has been replaced by the product of turbine mechanical power and mechanical efficiency. The only difference between the $\dot{W}_{T, s}$ and $\dot{W}_{T, s}^{a d}$ is the 
turbine inlet temperature; therefore it is possible to introduce turbine adiabatic efficiency in equation 54, as shown below:

$$
\begin{aligned}
E T E & =\eta_{T s}^{a d} \cdot \eta_{\text {mech }} \cdot\left(1+\frac{\dot{Q}_{C / A i r}}{\dot{W}_{C}}\right) \cdot\left(1-\frac{\dot{Q}_{T / \text { Gas }}}{T_{T G a s} \cdot \dot{m}_{T} \cdot c_{p, T}}\right) \\
& =\left(\eta_{T s}^{a d} \cdot \eta_{\text {mech }}+\frac{\dot{Q}_{C / \text { Air }}}{\dot{W}_{T, s}^{a d}}\right) \frac{T_{T G a s}^{a d}}{T_{T G a s}}
\end{aligned}
$$

Equation 55 is used for calculating the adiabatic efficiency from the almost-adiabatic test. The test is done by minimizing the internal and external heat losses. Hence, the adiabatic efficiency of the turbine is higher than effective turbine efficiency measured during the hot test. This is due to the mechanical efficiency and the heat losses in the turbine $\left(\mathrm{T}_{\text {TGas }}>\mathrm{T}_{\text {TGas }}^{a d}\right)$ have a higher weight than the heat flux added from the compressor side $\left(\dot{Q}_{C / \text { Air }}\right)$. As it can be observed in the Figure 16 as 'cold' series of points.

A methodology proposed by Payri $^{3}$ has been used to extrapolate the adiabatic turbine efficiency calculated from an almost-adiabatic test in blade speed ratio (Equation 56). In the adiabatic test, the BSR is calculated using the adiabatic inlet temperature $\left(\mathrm{T}_{\text {TGas }}^{a d}\right)$, and in case of hot test, the temperature $\left(\mathrm{T}_{\text {TGas }}\right)$ is used (Figure 17). Considering that the amount of energy provided in both the tests (adiabatic and Hot) is different for the same reduced speed. So, there is also a change in expansion ratio (lower for cold tests and higher for hot tests). Thus, the BSR is different in both tests.

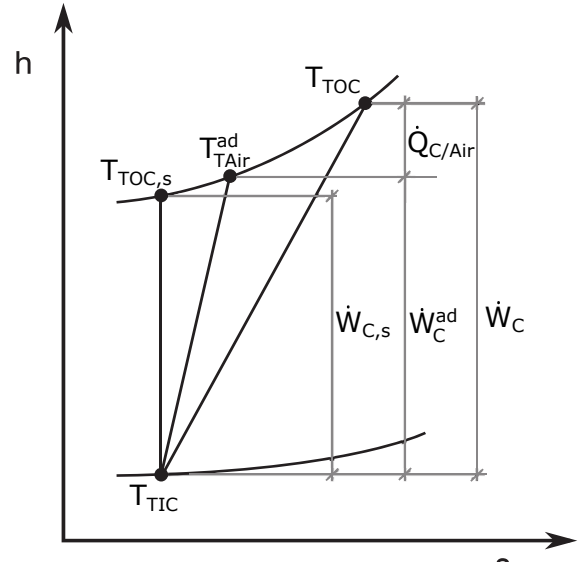

$\mathrm{S}$

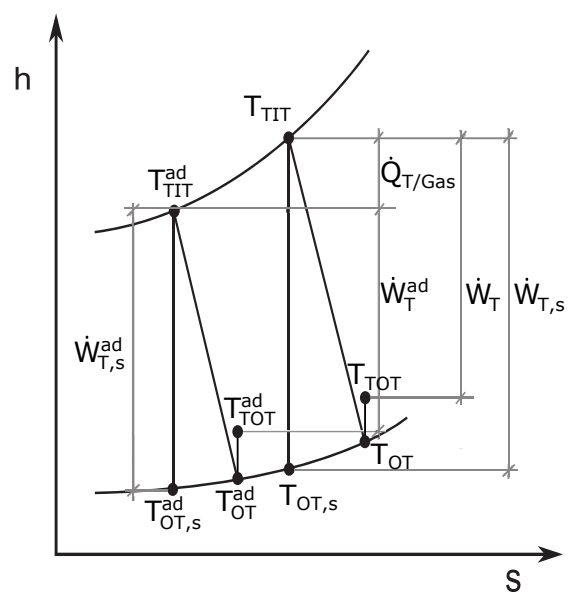

$\mathrm{S}$

Figure 17. Enthalpy-entropy chart of compression process (Left) and Expansion process (Right) 


$$
\begin{gathered}
\eta_{T s}^{a d}=\frac{\dot{W}_{T}^{a d}}{\dot{W}_{T s}^{a d}} \\
\sigma=\frac{u_{1}}{c_{s}}=\frac{\pi \cdot D_{T} \cdot N}{\sqrt{2 \cdot c_{p, T} \cdot T_{T G a s} \cdot\left(1-\Pi_{T}^{\left(\frac{1-\gamma}{\gamma}\right)}\right)}}
\end{gathered}
$$

Calculation procedure presented in previous sub-sections and with the help of models proposed by ${ }^{9,14,15}$ is used to discount the mechanical losses and heat transfer effects. The internal irreversibilities are taken into account by turbine efficiency after applying those models. In Figure 16, it is named as adiabatized. Now, the effective turbine efficiency (which is adiabatized) is higher than the ETE calculated from the hot steady test using Equation 53. It is because mechanical losses, turbine and compressor heat transfers are discounted with the help of the models. By looking at in Figure 1 and Equation 54 one can understand the importance of considering different heat fluxes in the turbocharger to calculate precisely the effective turbine efficiency. The effect of compressor heat transfer is less important but, at low turbocharger speeds it should be taken into account as the heat transfer to the compressor is high $\left(\dot{Q}_{C / A i r}\right)$ as shown in Figure 14 and 15 . However, at high turbocharger speeds, the turbine heat $\left(\dot{Q}_{T / \text { Gas }}\right)$ should be more important as the turbine power increases with increasing the turbine rotational speed and therefore the effect of heat transfer from the turbine significantly affects the effective turbine efficiency. In general, the mechanical efficiency is more or less a constant value but, only low at lower turbocharger speeds. It is observed that turbine efficiency(adiabatized) lies overextrapolated efficiency curve of the turbine which has been obtained from the almostadiabatic test, and the RMSE between them is not more than 0.0135 (from lower to higher turbo speeds). It is observed that there is also a change in BSR when the hot maps are converted into adiabatic maps. This is because the change in turbine inlet temperature from $T_{T \text { Gas }}$ to $T_{\text {TGas }}^{a d}$ (Figure 17), during the process making the adiabatic maps. As the adiabatic turbine inlet temperature is estimated by extracting the heat from the gas (Equation 42) before it expanded in the turbine stator.

The methodology is also applied on turbocharger T\#8 to obtain adiabatic maps from hot steady maps Figure 18. The results convinced that using the proposed calculation procedure; hot steady tests can be used in turbocharger simulations to obtain adiabatic maps. Figure 18 shows how the effect of adiabatization in ETE is more reduced than in Figure 16. It is due to both the active water cooling of the bearing housing that reduces heat transfer to the compressor, and the higher $T_{T G a s}$ that makes the ratio ( $T_{T \text { Gas }}^{\text {ad }} / T_{T \text { Gas }}$ ) closer to unity (Equation 43 ). As it is observed, this model can be used to obtain extra information for extrapolation purpose, since the adiabatized hot steady measurements are used to extrapolate peak efficiency region. Moreover, the available region is extrapolated by those measurements using almost-adiabatic information. 

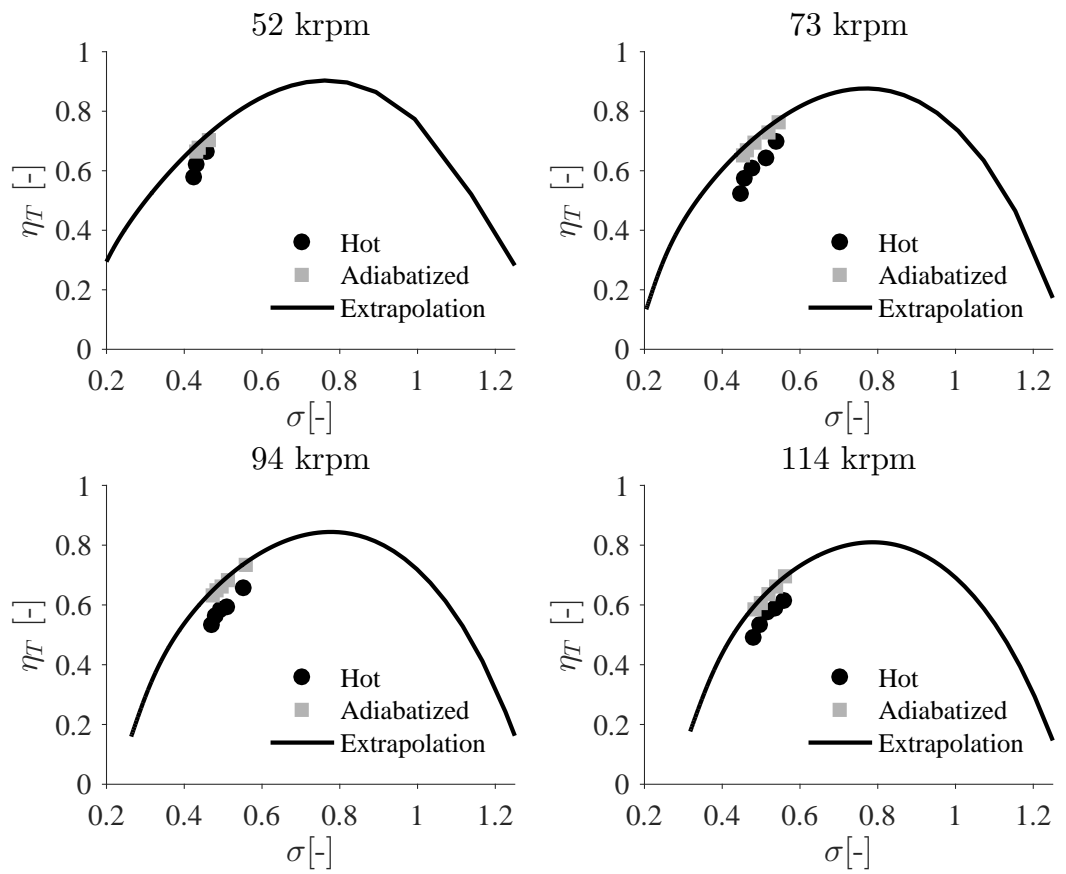

Figure 18. Comparison of turbine efficiencies from hot tests, proposed methodology adiabatization and extrapolation of adiabatized for $\mathrm{T \# 8}$

\section{Conclusions}

In this work, a general procedure for estimating the conductive conductances and capacitances for an automotive turbocharger was provided. These parameters are primarily to characterize the heat transfer model. The methodology is shown based on the material properties and simple geometrical information of the turbocharger as entry data to the model. For estimating the conductive conductance, a concrete definition for calculating the area with contact surface between the two metal nodes has been proposed. Both models (conductance and capacitance) are fitted with a variety of turbochargers which have different external geometries and including water cooled and non-water cooled. The model is additionally validated with the turbocharger T\#8 and shows considerable accordance with the measured values.

Based on the study conducted above, it can now safely be concluded that the outlet temperatures of the compressor and turbine can be determined adequately by using a heat transfer model and the adiabatic maps. Additionally, they are useful for extrapolation purpose too. Turbocharger manufacturers do not usually provide that information as they measure the performance maps under hot flow conditions. For that reason, a calculation procedure has been proposed in this work that determines the adiabatic maps 
for turbocharger through the means of hot measured maps. The results confirmed that using the proposed methodology; the turbocharger can be simulated by the hot steady test to obtain adiabatic maps. The extra information for extrapolation obtained from the model ${ }^{3}$ shows that the adiabatized hot steady measurements cover turbine peak efficiency region.

Furthermore, it is observed that adiabatic efficiencies of compressor and turbine obtained using hot steady measurements agreed with adiabatic efficiency obtained from the almost-adiabatic test. The method can be used for benchmarking of maps from several manufacturers measured at different operative conditions to check their highest level of aerodynamic efficiency. The method allows extracting adiabatic efficiency for comparison and also individual heat fluxes and heat transfer features. This method can also be used in 1D turbocharger model to generate the adiabatic maps and later on using the model for predicting the non measured turbocharger operative conditions.

\section{Acknowledgments}

This work has been partially supported by FEDER and the Government of Spain through Grant No: TRA2016-79185-R. We would like to thank technicians Valenín Ucedo and Miguel Ortiz for there assistance on controlling the turbocharger test rigs. 


\section{References}

1. Casey MV and Fesich TM. On the efficiency of compressors with diabatic flows. In Proceedings of the ASME Turbo Expo, volume 1. pp. 785-797. Cited By :13.

2. Sirakov B and Casey M. Evaluation of heat transfer effects on turbocharger performance. Journal of Turbomachinery 2012; 135(2). DOI:10.1115/1.4006608.

3. Payri F, Serrano JR, Fajardo P et al. A physically based methodology to extrapolate performance maps of radial turbines. Energy Conversion and Management 2012; 55: 149163. DOI:10.1016/j.enconman.2011.11.003.

4. Nakhjiri M, Pelz PF, Matyschok B et al. Apparent and real efficiency of turbochargers under influence of heat flow. In ISROMAC 2012 - 14th International Symposium on Transport Phenomena and Dynamics of Rotating Machinery.

5. Chesse P, Chalet D and Tauxia X. Impact of the heat transfer on the performance calculation of autmotive turbocharger compressor. Oil and Gas Science and Technology, Rev IFP Energies Nouvelles 2011; 66: 791-800. DOI:10.2516/ogst/2011129.

6. Sidorow A, Insermann R, Cianflone $\mathrm{F}$ et al. Compasrion of a turbocharger model based on isentropic efficiency maps with a parametric approach based on euler's turbo-machinery equation. In 18th IFAC World Congress, volume 44. pp. 10627-10632.

7. Zimmermann R, Baar R and Biet C. Determine the isentropic turbine efficiency due to adiabatic measurements and the validation of the conditions via a new criterion. In 12th International Conference on Turbochargers and Turbocharging, volume 1. pp. - .

8. Serrano JR, García-Cuevas LM, Inhestern LB et al. Methodology to evaluate turbocharger turbine performance at high blade to jet speed ratio under quasi adiabatic conditions. In Proceedings of the ASME Turbo Expo, volume 8. DOI:10.1115/GT2017-63360.

9. Serrano JR, Olmeda P, Arnau FJ et al. A study on the internal convection in small turbochargers. proposal of heat transfer convective coefficients. Applied Thermal Engineering 2015; 89: 587-599. DOI:10.1016/j.applthermaleng.2015.06.053.

10. Tanda G, Marelli S, Marmorato M et al. An experimental investigation of internal heat transfer in an automotive turbocharger compressor. Applied Energy 2017; 193: 531-539. DOI: 10.1016/j.energy.2017.02.053.

11. Romagnoli A and Martinez-Botas R. Non-adiabatic compressor efficiency of turbocharger: A statistical approach. In Proceedings of the ASME Turbo Expo, volume 5. pp. 495-506. DOI:10.1115/GT2010-23149.

12. Serrano J, Olmeda P, Arnau F et al. General procedure for the determination of heat transfer properties in small automotive turbochargers. SAE International Journal of Engines 2014; 8(1): 30-41. DOI:10.4271/2014-01-2857.

13. Serrano JR, Olmeda P, Páez A et al. An experimental procedure to determine heat transfer properties of turbochargers. Measurement Science and Technology 2010; 21(3). DOI: 10.1088/0957-0233/21/3/035109.

14. Payri F, Olmeda P, Arnau FJ et al. External heat losses in small turbochargers: Model and experiments. Energy 2014; 71: 534-546. DOI:10.1016/j.energy.2014.04.096.

15. Serrano JR, Olmeda P, Tiseira A et al. Theoretical and experimental study of mechanical losses in automotive turbochargers. Energy 2013; 55: 888-898. DOI:10.1016/j.energy.2013.04.042. 
16. Serrano JR, Arnau FJ, Andrés T et al. Experimental procedure for the characterization of turbocharger's waste-gate discharge coefficient. Advances in Mechanical Engineering 2017; 9(10). DOI:10.1177/1687814017728242.

17. SAE International. Turbocharger gas stand test code, SAE J1826. Technical report, Society of Automotive Engineers Inc, 1995. DOI:https://doi.org/10.4271/J1826_199503.

18. SAE International. Supercharger testing standard, SAE J1723. Technical report, Society of Automotive Engineers Inc, 1995. 